\title{
Evaluating Nonlinear Effective Stress Site Response Analyses using Records from the Canterbury Earthquake Sequence
}

\author{
Christopher S. Markhamª, Jonathan D. Bray ${ }^{\mathrm{b}}$, Jorge Macedo ${ }^{\mathrm{c}}$, and Roberto Luque ${ }^{\mathrm{d}}$ \\ aUniversity of California, Berkeley, 435 Davis Hall, Berkeley, CA 94720-1710, USA, \\ cmarkham@berkeley.edu, (510)289-1313 \\ bUniversity of California, Berkeley, 453 Davis Hall, Berkeley, CA 94720-1710, USA, \\ jonbray@berkeley.edu \\ 'University of California, Berkeley, 445 Davis Hall, Berkeley, CA 94720-1710, USA, \\ macedo@berkeley.edu \\ 'University of California, Berkeley, 435 Davis Hall, Berkeley, CA 94720-1710, USA, \\ roberto.luque@berkeley.edu \\ *Corresponding Author
}

(C) 2015. This manuscript version is made available under the Elsevier user license 


\begin{abstract}
A widely used one-dimensional nonlinear effective stress site response analysis program is used to model the response of potentially liquefiable soils during strong shaking. Ground motion records from six events of the 2010-2011 Canterbury earthquake sequence and the extensive site investigation data that have been obtained for the Christchurch area provide the basis for the analyses. The results of the analyses depend significantly on the input motions and soil profile characterization, so these important aspects are examined. Deconvolved Riccarton Gravel input motions were generated, because recorded rock or firm layer motions were not available. Nonlinear effective stress seismic site response analyses are shown to capture key aspects of the observed soil response through the comparison of acceleration response spectra of calculated surface motions to those of recorded surface motions; however, equivalent-linear and total stress nonlinear analyses capture these aspects as well. Biases in the computed motions compared to recorded motions were realized for some cases but they can be attributed primarily to the uncertainty in the development of the input motions used in the analyses.
\end{abstract}

Keywords

Effective stress analyses; Ground motions; Liquefaction; Nonlinear analyses; Seismic site response 


\section{Introduction}

The 2010-11 Canterbury earthquake sequence devastated much of Christchurch, New Zealand and its surrounding areas. Liquefaction during the 4 SEP 10 (moment magnitude, $\mathrm{M}_{\mathrm{w}} 7.1$ ) Darfield event affected approximately $10 \%$ of the Christchurch area; whereas the 22 FEB 11 $\left(M_{w} 6.2\right)$ Christchurch event affected over $50 \%$ of the developed land (see Figure 1). Including these two events, there were a total of seven events with moment magnitude $\left(\mathrm{M}_{\mathrm{w}}\right)$ greater than or equal to 5.5 between 4 SEP 2010 and 23 DEC 2011 which caused varying degrees of liquefaction in and around Christchurch.

The Canterbury earthquake sequence provides a great opportunity to examine soil response during strong seismic shaking, particularly as it relates to the effects of liquefaction. During the events discussed above, some sites within Christchurch liquefied as many as five times, other sites only liquefied once or twice, and other sites never experienced soil liquefaction. By taking advantage of the dataset provided by these earthquakes, our understanding of the performance of critical infrastructure during major shaking events with extensive and damaging liquefaction can be improved. Understanding the effects of liquefaction, however, starts with being able to capture reliably the seismic response of free-field sites that develop significant pore water pressures during earthquake shaking. Moreover, building codes commonly require that seismic site response analyses be performed to develop design earthquake ground motions at liquefiable sites. Improved methods for estimating earthquake ground motions at sites that contain liquefiable soils are required. However, there are relatively few recordings of ground motions at liquefied sites to evaluate current or new methods. Thus, the Canterbury earthquake sequence dataset is invaluable.

Previous studies, such as those by Matasovic and Vucetic (1993), Zehgal and Elgamal (1994), Youd and Carter (2005), Kramer et al. (2011), and Gingery et al. (2014), have provided useful insights regarding the effects of soil liquefaction on ground response during strong shaking $[1][2][3][4][5]$. This research focuses on evaluating the capabilities of one-dimensional (1D), nonlinear effective stress seismic site response analytical procedures to capture the seismic response of sites with and without significant earthquake-induced pore water pressure generation. Specifically, the widely used seismic site response program DEEPSOIL [6] was utilized to perform the analyses for this evaluation. The research capitalizes on the data provided by the GeoNet network of strong motion station recordings taken throughout the greater Christchurch area during the Canterbury earthquake sequence [7]. The site investigation data that have been collected by researchers and practitioners throughout Christchurch over the past several years were used in the estimation and selection of soil properties for the analyses presented in this paper. More in-depth information and results are presented in the final technical report that was submitted to the U.S. Geological Survey [8]. That report provides all characterization data considered for each strong motion station site, input parameters for seismic site response analyses, and analytical results.

\section{Canterbury Earthquake Sequence}

Seven events between 4 SEP 10 and 23 DEC 2011 had a $\mathrm{M}_{\mathrm{w}}$ greater than or equal to 5.5 during the Canterbury earthquake sequence. Of these seven events, seismic records from five earthquakes were examined in this study. In addition to these events with $\mathrm{M}_{\mathrm{w}} \geq 5.5$, the $\mathrm{M}_{\mathrm{w}} 4.7$ earthquake that occurred on 26 DEC 2010 was included in this study, because the shaking 
intensities resulting from this event were such that soil response was largely linear. Table 1 provides relevant information for each of the events studied. The horizontal acceleration records and respective 5\% damped pseudo-acceleration response spectra from each event at each strong motion station were employed to evaluate the results of the seismic site response analyses presented in this paper. All records were rotated to fault normal and fault parallel components based on the strike values listed in Table 1. Uniformly processed acceleration records for the 4 SEP 10 Darfield and 22 FEB 11 Christchurch events were available from the Pacific Earthquake Engineering Research (PEER) center [9]. Processed records for the remaining events were obtained from the GeoNet strong motion acceleration-time series database [7].

Figure 1 provides a map overview of the locations of the strong motion stations from which the seismic records for this study were obtained. Some of these sites showed signs of liquefaction in multiple events, which was evident in surface manifestation (i.e., sediment ejecta — see [11]) or distinct features of the surface recording (e.g., dilation spikes within the acceleration-time series - see [12]). Table 2 provides a detailed overview of relevant parameters for each strong motion station for the events studied. The 4 SEP 10 Darfield event had the largest moment magnitude of all the events shown in Table 1. However, it was the 22 FEB 11 Christchurch event that caused the most intense shaking in the greater Christchurch area, which is evidenced by the generally higher recorded peak ground accelerations for the stations presented in Table 2 . The relatively lower source-to-site distances of the Christchurch event compared to the Darfield event is the primary cause of its more intense shaking, which is illustrated in Table 2 (see [13] for further discussion).

\section{Subsurface Characterization of Strong Motion Station Sites}

Over 18,000 cone penetration tests (CPT) have been completed in the greater Christchurch area. Much of these site investigation data can be obtained directly through the Canterbury Geotechnical Database [16]. In addition to these data, much of the site investigation information necessary to characterize the strong motion stations of interest was obtained through the work of other researchers, particularly Prof. Wotherspoon of the Univ. of Auckland and his research collaborators [11]. Table 3 provides a summary of the site investigation data for each site. The information obtained from CPT data was crucial in defining the stratigraphy of the sites and in estimating the engineering properties of the subsurface materials through established correlations. The McGann et al. (2014) Christchurch specific CPT-V correlation [17] provided the primary means for estimating the shear wave velocity $\left(\mathrm{V}_{\mathrm{s}}\right)$ profiles of the strong motion station sites. Table 3 shows that no CPT data were available at the time of writing for the strong motion station sites at CACS, RHSC, SMTC and KPOC (primarily due to the presence of near surface gravelly soil). For such cases, $V_{\text {s }}$ profiles calculated and presented in [11] (which were based on the surface wave testing results of [18]) were used for site characterization purposes. All site characterization data and information, including CPTs, considered $\mathrm{V}_{\mathrm{s}}$ profiles, and assumed soil properties for analyses presented subsequently can be found in [8].

A simplified subsurface profile for Christchurch is shown in Figure 2. The subsurface is comprised generally of surficial deposits varying in thickness from less than $10 \mathrm{~m}$ to over $40 \mathrm{~m}$. These materials form the Springston Formation (primarily alluvial gravels, sands, and silts) in the western area of Christchurch and the Christchurch Formation (comprised of estuarine, lagoon, beach, dune, and coastal swamp deposits of sand, silt, and some clay, and peat) in the eastern part of the city [19]. Below these deposits lies the dense, well-graded Riccarton Gravel 
layer [20]. Most site investigations characterize only the soils that overlie the dense Riccarton Gravel. The estimated depth to the Riccarton Gravel layer at each site studied is also listed in Table 3.

\section{Selection of Input Ground Motions for Site Response Analyses}

All of the strong motion station sites of interest are situated within the Canterbury Plains. The general geology of this area comprises distinct layers of gravels interbedded with layers of primarily sands and silts, with some pockets of clays and peats, to a depth of over $500 \mathrm{~m}$ below the ground surface [20][21][22]. Figure 2 provides a simplified geologic profile of the Christchurch region. The depth to "basement" rock for soils underlying the Canterbury Plains can be over $2 \mathrm{~km}$ below the ground surface [23][24]. These deep sediment deposits coupled with the presence of the volcanic rock that makes up the Port Hills and Banks Peninsula to the southeast of central Christchurch create a basin structure.

The deep basin structure that underlies the studied sites makes the selection of representative "rock" input motions difficult due to the absence of outcropping "rock" recordings on the north side of the Port Hills (i.e., within Canterbury Plains side of the Port Hills). The Lyttelton Port strong motion station (LPCC) has a $\mathrm{V}_{\mathrm{s} 30}$ of about $792 \mathrm{~m} / \mathrm{s}$ according to the work of [18], placing it in the category of engineering bedrock (i.e., $B / C$ rock boundary for $\mathrm{V}_{\mathrm{s}} \approx 760 \mathrm{~m} / \mathrm{s}$ [25]). However, the location of LPCC with respect to the locations of the events of interest and seismic energy propagation from these events make it a non-ideal input motion for seismic site response analyses in the Christchurch area (e.g., LPCC is located on the southern side of the Port Hills as opposed to the northern side, it is a significant distance from downtown Christchurch, and it is on the hanging wall as opposed to the footwall for several events).

\subsection{Deconvolution of Surface Motions}

With the lack of representative "rock" input motions, as well as the difficulty in reliably characterizing the stratigraphy beneath the studied sites to the depth of engineering bedrock, deconvolving recorded surface motions to obtain input motions for a "firm" base material is required. An alternative would be to use synthetic "rock" motions for each event, but they are not currently available, and they will contain significant uncertainty when produced. Deconvolution consists of inputting an outcropping motion at the surface of a 1D soil column and using an equivalent-linear analysis to calculate the acceleration-time series at a point beneath the ground surface (see [26][27][28]). This within motion can be converted to an outcropping motion for use in subsequent convolution analyses.

Silva (1988) [27] outlines a procedure to help avoid the situation of unrealistic motions being calculated at depth due to the propagation of the total surface motion via an equivalent-linear analysis during the deconvolution process. These steps were adhered to and are as follows:

1.A low pass (LP) filter was applied to the recorded surface motion to be used for the deconvolution analysis at $15 \mathrm{~Hz}$ and scaled by 0.87 ; SeismoSignal ${ }^{\mathrm{TM}}$ was used to perform a $4^{\text {th }}$ order, LP Butterworth filter.

2. The filtered and scaled motion from step 1 was input at the surface of a 1D soil column.

3. This motion is transferred through the soil column to a predetermined half-space.

4. The final iteration values of shear modulus reduction $\left(\mathrm{G} / \mathrm{G}_{\max }\right)$ and material damping $(\lambda)$ for each layer during the deconvolution process is obtained.

5. The deconvolution process was performed again by using a linear analysis with the final 
values of $\mathrm{G} / \mathrm{G}_{\max }$ and $\lambda$ from step 4 for each layer of the $1 \mathrm{D}$ soil column and inputting the LP filtered $(15 \mathrm{~Hz})$ full surface motion (i.e., not scaled by 0.87$)$ at the top of the column to obtain a final within motion. This within motion was then converted to a final outcropping deconvolved motion for use as an input motion in convolution analyses. SHAKE2000 was utilized to perform all deconvolution analyses [31].

The dense Riccarton Gravel unit (see Figure 2b) was used as the "firm" half-space for deconvolution analyses and subsequent seismic site response analyses. The impedance contrast between the Riccarton Gravel and the softer overlying surficial deposits was on average two for the sites studied. The presence of this firm layer below the potentially liquefiable soils in the Christchurch area supported using the Riccarton Gravel unit as the half-space for deconvolution.

\subsubsection{Deconvolution at Selected Strong Motion Station Sites (CACS and RHSC) and Scaling of Input Motions}

The Canterbury Aero Club (CACS) and the Riccarton High School (RHSC) strong motion sites were used for the deconvolution procedure (see Figure 1). These sites are located on sites that did not show surface manifestations of liquefaction during any of the events of interest and are believed to have shown minimal nonlinear response during strong shaking. These points are important, because the required equivalent-linear approach to deconvolution cannot capture fully the nonlinear response of soils. Furthermore, as can be seen in Table 3, the depth to the Riccarton Gravel layer for these sites is the lowest among the 13 strong motion station sites studied, which requires the surface motion to be deconvolved over a relatively shallow profile.

For the deconvolution process, the strain-dependent normalized shear modulus reduction and material damping relationships presented by [32] were used for all material above the Riccarton Gravel. Two different $V_{s}$ profiles were initially considered for both the CACS and RHSC sites to account for the epistemic uncertainty in the site characterization of these stations. For CACS, both $V_{s}$ profiles were assumed based on the information presented by Wotherspoon et al. (2013) [11] and mostly differed by the assumed depth and $V_{s}$ of the Riccarton Gravel (see Figure 3a). For RHSC, one $\mathrm{V}_{\mathrm{s}}$ profile was estimated based on the work of Wood et al. (2011) [18] while the other was assumed from the work presented by Wotherspoon et al. (2013) [11]. Figure 3 provides the estimated $V_{s}$ profiles for the deconvolution sites. It was found that for a given deconvolution site, the input motions generated from the consideration of two different $\mathrm{V}_{\mathrm{s}}$ profiles yielded similar results for subsequent convolution analyses. The authors considered the Woth $1 \mathrm{~V}_{\mathrm{s}}$ profiles for both the CACS and RHSC sites to be more representative of field conditions than the alternative $\mathrm{V}_{\mathrm{s}}$ profiles. Consequently, results presented hereafter are based on the use of input motions CACS_Woth1 and RHSC_Woth1, which are named based on their respective $V_{s}$ profiles.

Deconvolved ground motions were scaled to account for differences in the site-to-source distance and $V_{s}$ of the Riccarton Gravel between the deconvolution sites and the sites where convolution analyses were performed. This scaling was completed using the New Zealand specific ground motion prediction equation outlined in Bradley (2013) - referred to as Bradley GMPE herein [33]. This model uses source, path, and site input parameters to generate period dependent pseudo-spectral acceleration $\left(S_{a}\right)$ values. For a given event the source parameters (e.g., $\mathrm{M}_{\mathrm{w}}, \mathrm{Z}_{\mathrm{tor}}$, dip) were the same; however, the shortest distance between sites and the event rupture plane (path parameter $\mathrm{R}_{\text {rup}}$ ) varied between deconvolution and convolution sites, as did the shear wave velocity of the Riccarton Gravel due to its differing depth across Christchurch. To 
account for these differences, a single scale factor was calculated to transfer outcropping deconvolved Riccarton Gravel motions from deconvolution sites to convolution sites. This scale factor was calculated by averaging (arithmetic mean) the period dependent factors of median $\mathrm{S}_{\mathrm{a}}$ at convolution sites to deconvolution sites predicted by the Bradley GMPE across all periods considered in the GMPE. A single factor was used to scale input motions as opposed to spectrally matching deconvolved motions to a smooth target response spectrum to retain the event-specific characteristics of the input acceleration-time series.

As stated previously, the only parameters that were varied in the Bradley GMPE between the convolution sites and the deconvolution sites for a given event were $R_{\text {rup }}$ and $V_{s 30}$, where $V_{s 30}$ was used as a proxy to account for the varying $\mathrm{V}_{\mathrm{s}}$ of the Riccarton Gravel. Shear wave velocity values for the Riccarton Gravel were estimated based on the work of Wotherspoon et al. (2013) and ranged from 300 to $460 \mathrm{~m} / \mathrm{s}$ for the sites studied. Representative deconvolved input motions are provided in Figure 4. These motions represent outcropping Riccarton Gravel motions that were used as input motions for analyses completed at the Christchurch Hospital (CHHC) strong motion station site; the scale factors used for this site were 2.61 and 1.47 for the input motions that resulted from the deconvolution process at the CACS and RHSC sites, respectively. Scale factors for all stations and all events are provided in Markham et al. (2014).

Equivalent-linear analyses were carried out at the deconvolution sites for the events studied to examine the ability of the deconvolution process to generate input motions capable of capturing key characteristics of recorded surface motions. The input motions for these analyses corresponded to deconvolved Riccarton Gravel motions from the other deconvolution site (e.g., CACS deconvolved motion was used as the input motion for a convolution analysis at RHSC). Figure 5 provides representative results of analyses completed for the $13 \mathrm{Jun} 2011 \mathrm{M}_{\mathrm{w}} 6.0$ event at the deconvolution sites. As will be discussed further in Section 6, residuals can be calculated to compare the pseudo-spectral acceleration $\left(\mathrm{S}_{\mathrm{a}}\right)$ values of recorded motions $\left(\mathrm{S}_{\mathrm{a} \text {-Recorded }}\right)$ to those of calculated surface motions ( $\left.\mathrm{S}_{\mathrm{a}-\mathrm{Predicted}}\right)$ using equivalent linear analyses. These residuals are defined as the difference between the natural logarithm of $\mathrm{S}_{\mathrm{a}-\mathrm{Recorded}}$ and $\mathrm{S}_{\mathrm{a}-\text { Predicted }}\left(\mathrm{i} . \mathrm{e}\right.$., $\delta=\ln \left(\mathrm{S}_{\mathrm{a}-}\right.$ Recorded $\left.)-\ln \left(\mathrm{S}_{\mathrm{a} \text {-Predicted }}\right)\right)$. Based on average residual $\left(\mu_{\delta}\right)$ values and standard deviation of residuals $(\sigma \delta)$, the results of the equivalent linear analyses generally capture the key characteristics of the recorded surface motion. The response spectra presented in Figure 5 and in Section 6 are plotted from periods of $0.067 \mathrm{~s}$ to $10 \mathrm{~s}$, because a low-pass filter at $15 \mathrm{~Hz}$ was applied during the deconvolution procedure. The maximum shear strains calculated during the deconvolution analyses were less than about $0.1 \%$ for the Christchurch event and lower for the other events. Hence, the use of equivalent-linear analysis was judged to be acceptable for the deconvolution.

\section{Seismic Site Response Analyses Overview}

Nonlinear effective stress, nonlinear total stress, and equivalent-linear 1D seismic site response analyses were performed for each station listed in Table 2 that recorded shaking for each event of interest (see Table 1). The seismic site response program DEEPSOIL was used to perform these analyses [6]. It is a widely used nonlinear time domain site response analysis program that utilizes a discretized multi-degree-of-freedom lumped parameter model of the 1D soil column. The hysteretic soil response is captured by a pressure-dependent hyperbolic model that represents the backbone curve of the soil along with the modified extended unload-reload Masing rules [6]. Some additional pertinent details are discussed below. 


\subsection{Representation of Strain Dependent Soil Response}

Correlations proposed by Darendeli (2001) were used to obtain initial estimates of normalized shear modulus reduction $\left(\mathrm{G} / \mathrm{G}_{\max }\right)$ and material damping $(\lambda)$ curves for each site where seismic site response analyses were completed [32]. In general, the soils for each subsurface profile were considered to be non-plastic $(\mathrm{PI}=0)$ and normally consolidated $(\mathrm{OCR}=1)$. The mean confining pressure for each layer $\left(\sigma^{\prime} \mathrm{m}\right)$ was estimated based on assumed unit weights of 17.3 $\mathrm{kN} / \mathrm{m}^{3}$ for all soils above the groundwater table and $19.6 \mathrm{kN} / \mathrm{m}^{3}$ for all soils below the groundwater table and an assumed $\mathrm{K}_{\mathrm{o}}$ value of 0.5 (i.e., $\sigma^{\prime} \mathrm{m}=2 / 3 \sigma_{\mathrm{v}}$ ). Event specific groundwater table depths for each strong motion station site were estimated from the Canterbury Geotechnical Database [34].

The Darendeli (2001) relationship tended to underestimate the assumed shear strength of the soils studied. The procedure proposed by [35] was utilized to remedy the potential misrepresentation of a soil's shear strength. This procedure allowed for the calculation of a "strength corrected" hybrid shear modulus reduction curve that transitions from the G/Gmax curve computed from the Darendeli (2001) relationship to a strength based $\mathrm{G} / \mathrm{G}_{\max }$ curve at a specific strain level. Due to a lack of published guidance in correcting the material damping curve to capture large strain response, a hybrid damping curve was calculated that transitioned from the damping curve calculated from the Darendeli (2001) relationship to a strength based material damping curve using a linear (in semi-log space) approximation. Figure 6 illustrates the corrections made to the target shear modulus reduction and material damping curves for the performed seismic site response analyses. Shear strength estimates for the subsurface soils at the strong motion sites were primarily based on correlations from in-situ site investigation data (i.e., CPT and SPT data from [11] and [16]).

The MRDF-UIUC pressure dependent, hyperbolic fitting procedure proposed by [36], which is implemented in DEEPSOIL, was used to fit the target (corrected) shear modulus reduction and material damping curves for all nonlinear (effective and total stress) analyses. The procedure proposed by [37] was followed for all nonlinear site response analyses to ensure that the implied shear strength of the fitted shear modulus reduction curve for a given material was approximately equal to the assumed shear strength. This procedure requires an iterative adjustment of the target shear modulus reduction curve to capture the assumed shear strength for a given material. The frequency independent small strain damping formulation proposed by [36] was used to calculate viscous damping for all nonlinear site response analyses.

Normalized shear modulus reduction values calculated via the procedure outlined in [35] were used directly at discrete values of shear strain for each layer of a given 1D soil profile for equivalent-linear analyses. The final material damping curves that resulted from the MRDFUIUC fitting procedure discussed above for nonlinear analyses were used to define values of material damping at discrete values of shear strain for equivalent-linear seismic site response analyses. The reason for the use of the fitted material damping curve versus the material damping curve obtained directly from the strength correction procedure is due primarily to the hyperbolic representation of the material damping curve that the fitted procedure provides as well as a better representation of material damping at large strains via the fitting procedure implemented in DEEPSOIL. The effective shear strain ratio $\left(\gamma_{\mathrm{ref}}\right)$ proposed by [38] and the frequency independent complex shear modulus discussed in [6] were used for all equivalent-linear analyses. 


\subsection{Parameters for Nonlinear Effective Stress Analyses}

This study consisted of primarily non-plastic, cohesionless soils. These soils were modelled using the pore water pressure generation model for sands originally developed by [39], modified by [40], and presented in [1]. Equation 1 provides the governing equation of this model:

$$
u_{N}^{*}=\frac{p * f * F * N *\left(\gamma_{c}-\gamma_{t v p}\right)^{s}}{1+f * F * N *\left(\gamma_{c}-\gamma_{t v p}\right)}
$$

The parameters for the pore water pressure generation model would ideally be selected based on curve fitting site specific, undrained, cyclic test results. Due to a lack of site specific information for the strong motion stations sites, the D-MOD2000 manual (see [41]) and the work of [42] were used in the selection of parameters. Based on this information, the following logic was used in the selection of parameters:

- $f$ was assumed to be 2 for all analyses; this value was used to better represent 2D shaking in the pore water pressure generation model (analyses were also performed with $f=1$ and 1.5 to evaluate the sensitivity of the results to this parameter); the maximum $r_{u}$ value was set to 0.99

- $\quad p$ was assumed to be 1 for all analyses

- $\gamma_{\text {tvp }}$ was chosen based on the value of shear strain $(\gamma)$ at $\mathrm{G} / \mathrm{G}_{\max }=0.65$

- In general, $F$ was chosen based on the guidance of the correlation presented by [42] that uses the soil information from [41] to correlate $F$ to shear wave velocity $\left(\mathrm{V}_{\mathrm{s}}\right.$ in $\left.\mathrm{m} / \mathrm{s}\right)$. In some cases $F$ was adjusted to prevent unrealistic large shear strains or unexpected high pore water pressure generation (e.g., in a layer of silty clay material directly above the Riccarton Gravel). The correlation used for $\mathrm{F}$ is:

$$
F=3810 * V_{s}^{-1.55}
$$

- $s$ was chosen based on a similar correlation from [42] which relates this parameter to fines content (FC in percent):

$$
s=(F C+1)^{0.1252}
$$

where FC was correlated from CPT data using the average CPT Ic-FC correlation proposed by [43], which largely enveloped the Christchurch data presented by [44].

The degradation of both the stiffness and strength of a liquefied soil is then represented through the modification of the MKZ hyperbolic model as proposed by [1] and [45] through the use of the above pore water pressure generation model. The additional exponent $v$ considered by [1] in the calculation of the degradation parameter was incorporated into the analyses. A value of $v$ equal to 3.8 was assumed for all materials based on the recommendation of [1].

Excess pore water pressure dissipation and redistribution can be accounted for simultaneously with the generation of excess pore water pressure in a nonlinear effective stress analysis. The dissipation and redistribution of excess pore water pressure is modeled using Terzaghi's 1D consolidation theory. The solution process of DEEPSOIL assumes dissipation only in the vertical direction [6]. This model requires only the specification of the coefficient of consolidation $\left(c_{v}\right)$, 
which was estimated based on CPT correlations. Additionally, a permeable boundary was used for the bottom layer within DEEPSOIL to represent the Riccarton Gravel. Its $\mathrm{c}_{\mathrm{v}}$ value is set by the program to be that of the bottom soil layer, which was at least $0.1 \mathrm{ft}^{2} / \mathrm{s}$ for all sites.

\section{Results and Discussion}

The results presented and discussed herein correspond to analyses completed using input motions from the deconvolution of the CACS and RHSC surface motions using the $\mathrm{V}_{\text {s }}$ profiles named Woth1, as discussed in Section 4.1.1. Analyses were completed for each event and SMS site listed in Table 2. No analyses were completed for cases where there were no recordings for a particular station (e.g., CCCC for the 13 JUN 2011 earthquake-Table 2). For the 26 DEC 2010 event only input motions generated from deconvolution at the CACS site were considered as no recordings were taken at the RHSC site for this event.

The recordings at each station for each event provide a means for assessing the results of the calculated surface motions from the seismic site response analyses completed at each site. Pseudo-acceleration response spectra (5\% damped; abbreviated as acceleration response spectra hereafter) were used to simplify the comparisons between recorded surface motions and those calculated from analyses. As a low-pass filter was applied at $15 \mathrm{~Hz}$ to the motions used in the deconvolution process (see Section 4.1), response spectra are plotted with a minimum period of $0.067 \mathrm{~s}$ when comparing analytical results to the response spectra of recorded motions. Spectral acceleration residuals (referred to as residuals hereafter) were considered on a period-by-period basis to quantify the "fit" of acceleration response spectra calculated from analyses to those of recorded surface motions. The residuals are calculated as:

$$
\delta\left(T_{i}\right)=\ln \left(S_{a_{\text {recorded }}}\right)_{T_{i}}-\ln \left(S_{a_{\text {predicted }}}\right)_{T_{i}}
$$

Figure 7 shows the calculated surface acceleration-time series for analyses completed at the CHHC strong motion station site using the fault normal component (FN) of the CACS Woth1 input motion for the Christchurch event. The recorded motion is also shown. Figure 8 shows the calculated acceleration response spectra of these motions as well as those from the effective stress analysis completed using the RHSC Woth1 input motion. The plots on the right-hand side of Figure 8 show the period dependent residuals for each analysis. Also displayed is the average (arithmetic mean) residual across all periods as well as the standard deviation of residuals for each analysis. Based on the average residual, it can be seen that the analyses resulting from the use of the CACS Woth1 input motion compare better to the recorded surface motion (as opposed to those from the use of the RHSC Wothl input motion). This better matching with input motions that were a result of deconvolution at the CACS site was not always necessarily true for the other events studied; however, it was the general trend for the Christchurch event.

Interestingly, the acceleration response spectra of the surface motions calculated at the CHHC site by the equivalent-linear (EQL), total stress (TS), and effective stress (ES) nonlinear analyses were similar, as shown in Figure 8. Figure 9 shows plots of the maximum calculated shear strain, maximum pore water pressure ratio $\left(r_{u}\right)$, and maximum acceleration with depth for each analysis of the CHHC site in the fault normal direction using the CACS Woth1 input motion. The excess pore water pressure ratios calculated with the effective stress analysis are in excess of 0.94 at depths of 17-19 m. The calculated maximum shear strain at these depths of higher maximum $r_{u}$ 
are considerably larger than maximum shear strains calculated using the total stress nonlinear analysis and the equivalent-linear analysis.

Sensitivity analyses were completed to examine the effects of pore water pressure generation on the calculated soil response by using values of $f$ (see Section 5.2) equal to 1 and 1.5 for the pore water pressure model implemented in DEEPSOIL. Lower values of $f$ yielded lower values of $r_{u}$ and lower shear strains but did not have an appreciable effect on the calculated response spectra. Furthermore, as was typical for analyses conducted in this study, there were only slight differences between the acceleration response spectra of calculated surface motions that resulted from nonlinear total stress and effective stress analyses, as well as equivalent-linear analyses, for a given 1D soil column using the same input motion.

Figure 10 provides a comparison of response spectra of surface motions from analyses completed at the PPHS site for the Darfield event and the recorded surface motion in the fault parallel direction. On average analyses from both input motions result in underestimations when compared to the acceleration response spectrum of the recorded motion, though again the $C A C S$ Woth1 input motion resulted in average residuals being closer to zero. The spectral acceleration values are generally slightly higher for the TS analysis compared to the ES analysis for periods between 0.067 and $0.2 \mathrm{~s}$, while both are higher than the EQL analysis in this period range. Beyond this period range there is not a significant difference between the spectral acceleration values for the three types of analyses for the same input motion. Though the acceleration response spectra of the surface motions calculated from effective stress and total stress analyses are similar, it can be seen from Figure 11 that significant excess pore water pressures are indicated at a depth of about 3-5 m, with a max $r_{u}$ of 0.95 calculated at a depth of $4 \mathrm{~m}$. The Boulanger and Idriss (2014) CPT-based simplified liquefaction triggering procedure [46] generally agreed well with the effective stress analyses' calculated excess pore water pressure with depth (i.e., layers with $r_{u}$ values over 0.5 to 0.6 generally had $\mathrm{FS}_{\text {liq }} \leq 1$ ).

To examine trends in the results of seismic site response analyses performed for a given event, one can examine plots of residuals as a function of period for all stations where analyses were completed for a particular event. Figure 12 summarizes the results of the nonlinear effective stress analyses of all sites for the Christchurch event using the CACS Woth1 input in the fault normal direction. As was previously mentioned, residuals are only presented for periods greater than $0.067 \mathrm{~s}$ due to the use of a low-pass filter during the deconvolution process. In general, the results of the effective stress analyses compared well with the recorded motions at the sites studied, which can be seen in Figure 12 via the fact that most of the residuals are between \pm 0.5 across the period range of interest.

In addition to effective stress analyses completed using DEEPSOIL, a series of $1 \mathrm{D}$ analyses were completed using the finite-difference code FLAC (Fast Lagrangian Analysis of Continuasee [47]). The constitutive model PM4Sand developed by [48] was utilized to model the dynamic response of the soil. This model is a critical-state compatible, stress-ratio based, boundingsurface plasticity model for sands that modifies the model outlined in [49] and [50] to better capture the response of liquefiable soils. These analyses were completed only for a selection of sites for the Christchurch event to further examine the capability of the generated input motions to capture soil response using a different analysis procedure.

Figure 13 shows the computed response spectra for the calculated surface motions from the analyses completed using DEEPSOIL and FLAC at the Christchurch Botanical Gardens strong motion station (CBGS) using the CACS Woth1 FN input motion. As can be seen for this case, the FLAC analysis resulted in a better match of both the shape and amplitude of the recorded 
motion's response spectrum, especially from 0.1 to $1 \mathrm{~s}$. The variation in the calculated response spectra presented in Figure 13 could be due to the representation of the soil's stress-strain behavior via the PM4Sand constitutive model implemented in FLAC versus the $M K Z$ model implemented in DEEPSOIL. A comparison of shear stress vs. shear strain response of a soil layer due to the differing pore water pressure models is shown in Figure 14. The more advanced PM4Sand model appears to capture the nonlinear response of the liquefied soil better. However, a more exhaustive study would need to be completed to confirm the reasons for these differences.

Figure 15a shows a plot of residuals for all nonlinear effective stress analyses using the $C A C S$ Woth1 input motion for the Darfield event. There is a consistent positive "bump" in the residuals across all stations for periods between $1 \mathrm{~s}$ and approximately $6 \mathrm{~s}$. The consistent underestimation of the spectral accelerations within this period range is most likely due to the input motion's inability to fully replicate the forward directivity effects or basin response experienced at the strong motion stations in the eastern stations during the Darfield event. Figure 15b presents the residuals for the effective stress analyses completed using the RHSC Woth1 FN input motion. Now there is a general underestimation of the spectral acceleration values for periods greater than $1 \mathrm{~s}$, but on a much less pronounced scale compared to those shown in Figure 15a. The RHSC recording is classified as a velocity-pulse-type motion for the Darfield event based on the Hayden et al. (2014) procedure; whereas, the CACS recording is not. Consequently, the RHSC Woth 1 motion should be superior to the CACS Woth1 motion at estimating the response for periods in the 1 to $6 \mathrm{~s}$ range for those sites that were also identified as having velocity-pulse-type motion for the Darfield event. A proper characterization of the input motion is thus critical for calculating reasonable responses at the ground surface.

\section{Conclusions}

The 2010-11 Canterbury earthquake sequence provides an exceptional opportunity to investigate how the same ground responded to several significant earthquakes that delivered different intensities and durations of strong shaking. The ground near some of these strong motion station sites liquefied multiple times during the sequence; whereas other sites never liquefied. The seismic recordings at these sites were utilized to evaluate the capabilities of nonlinear 1D effective stress seismic site response analyses.

One of the greatest sources of uncertainty with most seismic site response analyses is the characterization of input motions. The deep basin structure that underlies much of Christchurch and the lack of recorded "rock" motions in the area of interest makes the selection of input motions for site response analyses in Christchurch challenging. This study generated deconvolved surface motions from two firm soil sites to provide input motions at the top of the dense Riccarton Gravel unit for the analyses. With the uncertainty introduced by using this procedure for generating input motions, some consistent biases were evident in the results of analyses compared to recorded surface motions for some events using a particular input motion; however, reasonable trends in the seismic response of sites that did or did not liquefy during the Canterbury earthquake sequence were observed.

Effective stress analyses did capture the generation of pore water pressure during strong shaking in critical layers. The generation of substantial excess pore water pressures in key layers generally agreed with the results of the empirical CPT-based liquefaction triggering procedures. However, even for cases where substantial excess pore water pressures were indicated within the 
subsurface of a given 1D soil column (i.e., $r_{u}$ values in excess of 0.95 ), there were typically only minor differences between the acceleration response spectra of surface motions calculated using nonlinear total stress and effective stress analyses.

Given the wealth of subsurface data available, it would be advantageous to install at least one down-hole array in Christchurch to measure accelerations at various depths within a soil profile (including the top of the Riccarton Gravel layer and in bedrock) as well as pore water pressures in the shallow liquefiable soils to assist in the calibration of input parameters for future analyses. Also, the generation of synthetic "rock" or "Riccarton Gravel" motions for Christchurch to be used as representative input motions for seismic site response analyses would be beneficial to future studies.

\section{Acknowledgments}

Research supported by the U. S. Geological Survey (U.S.G.S.), Department of Interior, under USGS award number G13AP00029 and the financial support of the USGS is gratefully acknowledged. We would also like to thank Dr. Liam Wotherspoon of the University of Auckland, Drs. Misko Cubrinovski and Brendon Bradley of the University of Canterbury, and Drs. Ken Stokoe and Brady Cox of the University of Texas at Austin for sharing data and providing advice during the conduct of this research. We would also like to thank the N.Z. government, and in particular the EQC and GNS Science who fund the GeoNet program, for the sharing of data. We also thank Dr. Sjoerd van Ballegooy and Mr. Mike Jacka of Tonkin \& Taylor, Ltd, who shared data and insights. Our collaborative interactions with Professor Thomas O'Rourke of Cornell University and Professor Russell Green of Virginia Tech on several joint NZ-US research projects have informed this study. Lastly, we thank James Gingery and Professor Ahmed Elgamal of the University of California San Diego, whose collaborative work on seismic site response of liquefiable soil sites also informed this study.

Figure 1 was created from maps or data extracted from the Canterbury Geotechnical Database (https://canterburygeotechnicaldatabase.projectorbit.com), which were prepared or compiled for the Earthquake Commission (EQC) to assist in assessing insurance claims made under the Earthquake Commission Act 1993. The source maps and data were not intended for any other purpose. EQC and its engineers, Tonkin \& Taylor, have no liability for any use of the maps and data or for the consequences of any person relying on them in any way.

\section{References}

[1] Matasovic, N. and Vucetic, M. (1993a). "Seismic response of composite horizontallylayered soil deposits," Research Report, Civil Engineering Dept. Univ. of California, Los Angeles, CA, March.

[2] Zehgal, M. and Elgamal, A. (1994). "Analysis of site liquefaction using earthquake records," J. Geotech. and Geoenvr. Engr., ASCE, 120(6), pp. 996-1017.

[3] Youd, T.L. and Carter, B.L. (2005). "Influence of soil softening and liquefaction on spectral acceleration," J. Geotechnical and Geoenvironmental Engineering, ASCE, 131(7). 
[4] Kramer, S.L., Hartvigsen, A.J., Sideras, S.S., Ozener, P.T. (2011). "Site response modeling in liquefiable soil deposits," 4th IASPEI / IAEE International Symposium, Effects of Surface Geology on Seismic Motions, Santa Barbara, California.

[5] Gingery, J.R., Elgamal, A., and Bray, J.D. (2014) "Response Spectra at Liquefaction Sites during Shallow Crustal Earthquakes.” Earthquake Spectra, In-Press, http://dx.doi.org/10.1193/101813EQS272M.

[6] Hashash, Y.M.A. (2012). "DEEPSOIL V5.1, User Manual and Tutorial 2002-2012." Department of Civil and Environmental Engineering, University of Illinois at UrbanaChampaign.

[7] GeoNet database of processed strong motion records for New Zealand. Accessed June 2014: ftp://ftp.geonet.org.nz/strong/processed/Proc

[8] Markham, C., Macedo, J., and Bray, J. D. (2014). "Evaluating Fully Nonlinear Effective Stress Site Response Analyses using Records from the Canterbury Earthquake Sequence.” U.S.G.S. Award No.: G13AP00029. August 29, 2014. Final Technical Report. Download from: http://earthquake.usgs.gov/research/external/reports/G13AP00029.pdf

[9] Pacific Earthquake Engineering Research Center, "PEER Ground Motion Database." Website accessed on June 2014. http://peer.berkeley.edu/nga/

[10] Canterbury Geotechnical Database (2013) "Liquefaction Interpreted from Aerial Photography", Map Layer CGD0200 - 11 Feb 2013, retrieved [23 Jan 2015] from https://canterburygeotechnicaldatabase.projectorbit.com/

[11] Wotherspoon, L.M., Orense, R.P., Bradley, B.A., Cox, B.R., Wood, C.M. \& Green, R.A. (2013). "Geotechnical characterisation of Christchurch strong motion stations." Earthquake Commission Biennial Grant Report, Project No. 12/629; 2013.

[12] Bradley B.A. and Cubrinovski M. (2011). "Near-source strong ground motions observed in the 22 February 2011 Christchurch earthquake." Bulletin of the New Zealand Society for Earthquake Engineering. Vol. 44, No. 4, December 2011.

[13] Kaiser, A., C Holden, J Beavan, D Beetham, R Benites, A Celentano, D Collett, J Cousins, M Cubrinovski, G Dellow, P Denys, E Fielding, B Fry, M Gerstenberger, R Langridge, C Massey, M Motagh, N Pondard, G McVerry, J Ristau, M Stirling, J Thomas, SR Uma \& J Zhao (2012). “The Mw 6.2 Christchurch earthquake of February 2011: preliminary report.” New Zealand Journal of Geology and Geophysics, 55:1, 6790.

[14] Ristau, J. 2008. "Implementation of routine regional moment tensor analysis in New Zealand." Seismological research letters, 79(3): 400-415.

[15] Bradley, B.A., Quigley, M.C., Van Dissen, R.J., Litchfield, N.J. (2014). "Ground Motion and Seismic Sources Aspects of the Canterbury Earthquake Sequence.” Earthquake Spectra. Preprint.

[16] Canterbury Geotechnical Database (2013). Site Investigation Data. Website accessed June 2014: https://canterburygeotechnicaldatabase.projectorbit.com.

[17] McGann, C., Bradley, B., Taylor, M., Wotherspoon, L., and Cubrinovski, M. (2014). "Development of an empirical correlation for predicting shear wave velocity of Christchurch soils from cone penetration test data." Soil Dynamics and Earthquake Engineering, 00(0), 15-27. 
[18] Wood, C.M., Cox, B.R., Wotherspoon, L.M. \& Green, R.A. (2011) "Dynamic site characterization of Christchurch strong motion stations" Bulletin of the NZSEE, 44(4): 195-204.

[19] Cubrinovski, M., Green, R.A., Wotherspoon, L., eds. (2011). "Geotechnical Reconnaissance of the 2011 Christchurch Earthquake." Technical Report. Retrieved from: http://geerassociation.org/GEER_Post\%20EQ\%20Reports/Christchurch_2011/Index_Christ church_2011.html.

[20] Brown, L.J. and Weeber, J.H. (1992). "Geology of the Christchurch Urban Area." Scale 1:25000. Institute of Geological and Nuclear Sciences geological map 1.

[21] Brown, L.J., and Wilson, D.D. (1988). "Stratigraphy of late Quaternary deposits of the northern Canterbury Plains, New Zealand." New Zealand Journal of Geology and Geophysics 31: 305-335.

[22] Forsyth, P.J., Barrell, D.J.A., and Jongens, R. (compilers). (2008). "Geology of the Christchurch area." Institute of Geological \& Nuclear Sciences 1:250 000 geological map 16. 1 sheet +67 p. Lower Hutt, New Zealand. GNS Science.

[23] Brown, L.J., Beetham, R.D., Paterson, B.R., and Weeber, J.H. (1995). "Geology of Christchurch, New Zealand: Environmental and Engineering Geoscience.” 1, 427-488.

[24] Hicks, S.R. (1989). "Structure of the Canterbury Plains, New Zealand from gravity modelling. " Geophysics Division, Department of Science and Industrial Research: Wellington.

[25] Minimum Design Loads for Buildings and Other Structures. ASCE 7-10.

[26] Kramer, S. L. (1996). Geotechnical Earthquake Engineering. Prentice Hall, Upper Saddle River, N.J.

[27] Silva, W. J., (1988). "Soil response to earthquake ground motion", EPRI Report NP5747, Electric Power Research Institute, Palo Alto, California.

[28] Idriss, I.M. and Akky, M.R. (1979). "Primary Variables Influencing Generation of Earthquake Ground Motions by a Deconvolution Process." Paper K 1/3. Proceedings of the 5th Annual SMiRT Conference, August 1979.

[29] Browne, G.H., and Naish, T.R. (2003). "Facies development and sequence architecture of a Late Quaternary fluvial-marine transition, Canterbury Plains and shelf, New Zealand: implications for forced regressive deposits." Sedimentary Geology 158: 57-86.

[30] SeismoSignal. Version 5.1.0. Build 200. SeismoSoft.

[31] Ordonez, G. (2000) "SHAKE2000," commercial software for performing seismic site response analysis.

[32] Darendeli, M. B. (2001). "Development of a new family of normalized modulus reduction and material damping curves," Ph. D., University of Texas at Austin, Austin, Texas.

[33] Bradley, B.A. (2013). "A New Zealand-Specific Pseudospectral Acceleration GroundMotion Prediction Equation for Active Shallow Crustal Earthquakes Based on Foreign Models." Bulletin of the Seismological Society of America. Vol. 103, No. 3, pp. 18011822, June 2013.

[34] Canterbury Geotechnical Database (2013). "EQC Event Specific Groundwater Surface Elevations." Map Layer CGD0800. 06 Sep 2014. Retrieved 23 Jan 2015 from https://canterburygeotechnicaldatabase.projectorbit.com/

[35] Yee, E., Stewart J.P., Tokimatsu K. (2013). "Elastic and Large-Strain Nonlinear Seismic Site Response from Analysis of Vertical Array Recordings.” J. Geotech. Geoenviron. Eng.139(10). 
[36] Phillips, C., and Hashash, Y. M. (2009). "Damping formulation for nonlinear 1D site response analyses." Soil Dynamics and Earthquake Engineering, 29(7), 1143-1158.

[37] Hashash, Y.M.A., Groholski, D.R. Phillips, C.A., (2010). "Recent advances in non-linear site response analysis." In proceedings of Fifth International Conference on Recent Advances in Geotechnical Earthquake Engineering and Soil Dynamics, May 24-29, San Diego, CA.

[38] Idriss, I. M., and Sun, J. I. (1992). "SHAKE91: A computer program for conducting equivalent linear seismic response analyses of horizontally layered soil deposits." Department of Civil and Environmental Engineering, University of California Davis.

[39] Dobry, R., Pierce, W. G., Dyvik, R., Thomas, G. E., and Ladd, R. S. (1985). "Pore pressure model for cyclic straining of sand." Rensselaer Polytechnic Institute, Troy, New York.

[40] Vucetic, M., and Dobry, R. (1988). "Cyclic triaxial strain controlled testing of liquefiable sands." Advanced Triaxial Testing of Soil and Rock, ASTM STP 977, American Society for Testing and Materials, Philadelphia, 475-485.

[41] Matasovic, N. and Ordóñez, G.A. (2012). "D-MOD2000 - A Computer Program for Seismic Site Response Analysis of Horizontally Layered Soil Deposits, Earthfill Dams, and Solid Waste Landfills." GeoMotions, LLC; Lacey, Washington, USA.

[42] Carlton, B. (2014). "An Improved Description of the Seismic Response of Sites with High Plasticity Soils, Organic Clays, and Deep Soft Soil Deposits.” PhD Thesis. University of California, Berkeley.

[43] Robertson, P.K. and Wride, C.E. (1998). "Evaluating cyclic liquefaction potential using the cone penetration test." Can. Geotech. J., 35, 442-459.

[44] Robinson, K., Cubrinovski, M., Bradley, B.A. (2013). "Sensitivity of predicted liquefaction-induced lateral displacements from the 2010 Darfield and 2011 Christchurch Earthquakes." 2013 NZSEE Conference.

[45] Matasovic, N., and Vucetic, M. (1993b). "Cyclic Characterization of Liquefiable Sands." ASCE Journal of Geotechnical and Geoenvironmental Engineering, 119(11), 1805-1822.

[46] Boulanger, R.W. and Idriss, I.M. (2014). "CPT and SPT Based Liquefaction Triggering Procedures.” Report No. UCD/CGM-14/01. Center for Geotechnical Modeling, Dept. of Civil and Environmental Engineering, University of California, Davis.

[47] Itasca (2009). Flac - Fast Lagrangian Analysis of Continua, Version 6.0, Itasca Consulting Group, Inc., Minneapolis, Minnestota.

[48] Boulanger RW, Ziotopoulou K. PM4Sand (Version 2): A sand plasticity model for earthquake engineering applications. Report no. UCD/CGM-12/01, center for Geotechnical Modeling, Department of Civil and Environmental Engineering, University of California, Davis, CA; 2012, 100 pp.

[49] Manzari, M.T., and Dafalias, Y. F. (1997). "A critical state two-surface plasticity model for sand." Geotechnique, 47(2), 255-272.

[50] Dafalias, Y.F., and Manzari, M. T. (2004). "Simple plasticity sand model accounting for fabric change effects." Journal of Engineering Mechanics, ASCE, 130(6), 622-634. 
Table 1: Information for events examined from Canterbury earthquake sequence

\begin{tabular}{|c|c|c|c|c|c|c|c|c|}
\hline Event & Date & $\begin{array}{c}\text { NZ Local } \\
\text { Time }\end{array}$ & $\mathbf{M}_{\mathbf{w}}$ & $\begin{array}{c}\text { Hypocentral } \\
\text { Latitude }\end{array}$ & $\begin{array}{c}\text { Hypocentral } \\
\text { Longitude }\end{array}$ & $\begin{array}{c}\text { Strike } \\
\left({ }^{\circ}\right)\end{array}$ & $\begin{array}{c}\text { Dip } \\
\left({ }^{\circ}\right)\end{array}$ & $\begin{array}{c}\mathbf{Z}_{\text {tor }} \\
(\mathbf{k m})\end{array}$ \\
\hline \hline 1 & 4 SEP 10 & $04: 35: 46$ & 7.1 & -43.5382 & 172.1635 & 85 & 82 & 0.0 \\
\hline 2 & 26 DEC 10 & $10: 30: 15$ & 4.7 & -43.5544 & 172.6615 & 74 & 84 & 2.0 \\
\hline 3 & 22 FEB 11 & $12: 51: 42$ & 6.2 & -43.5644 & 172.6915 & 50 & 64 & 0.5 \\
\hline 4 & 13 JUN 11 & $14: 20: 50$ & 6.0 & -43.5638 & 172.7431 & 162 & 67 & 1.4 \\
\hline 5 & 23 DEC 11 & $12: 58: 36$ & 5.8 & -43.4862 & 172.7957 & 45 & 63 & 0.0 \\
\hline 6 & 23 DEC 11 & $14: 18: 02$ & 5.9 & -43.5300 & 172.7428 & 57 & 51 & 1.5 \\
\hline
\end{tabular}

Notes:

1) Moment magnitudes obtained from GeoNet (www.geonet.org.nz) regional Centroid Moment Tensor (CMT) solutions [14]

2) Strike, dip, and $Z_{\text {tor }}$ values are based on Metadata received from Bradley (2013) via personal communication, except for the 22 FEB 11 event; the 22 FEB 11 values are based on [12] 
Table 2: Characteristics of event parameters at strong motion stations

\begin{tabular}{|c|c|c|c|c|c|c|c|c|c|c|c|c|}
\hline \multirow{2}{*}{ Station } & \multicolumn{2}{|c|}{$\begin{array}{c}4 \text { SEP } 10 \\
M_{w} 7.1\end{array}$} & \multicolumn{2}{|c|}{$\begin{array}{c}26 \text { DEC } 10 \\
M_{w} 4.7\end{array}$} & \multicolumn{2}{|c|}{$\begin{array}{c}22 \text { FEB } 11 \\
M_{w} 6.2\end{array}$} & \multicolumn{2}{|c|}{$\begin{array}{c}13 \mathrm{JUN} 11 \\
\mathrm{M}_{\mathrm{w}} 6.0\end{array}$} & \multicolumn{2}{|c|}{$\begin{array}{c}23 \text { DEC } 11 \\
M_{w} 5.8\end{array}$} & \multicolumn{2}{|c|}{$\begin{array}{c}23 \text { DEC } 11 \\
M_{w} 5.9\end{array}$} \\
\hline & $\begin{array}{c}\text { PGA } \\
\text { (g) }\end{array}$ & $\begin{array}{l}\text { R }_{\text {rup }} \\
\text { (km) }\end{array}$ & $\begin{array}{c}\text { PGA } \\
\text { (g) }\end{array}$ & $\begin{array}{l}\text { Rrup } \\
\text { (km) }\end{array}$ & $\begin{array}{c}\text { PGA } \\
\text { (g) }\end{array}$ & $\begin{array}{l}\text { R }_{\text {rup }} \\
\text { (km) }\end{array}$ & $\begin{array}{c}\text { PGA } \\
\text { (g) }\end{array}$ & $\begin{array}{l}\mathbf{R}_{\text {rup }} \\
\text { (km) }\end{array}$ & $\begin{array}{c}\text { PGA } \\
\text { (g) }\end{array}$ & $\begin{array}{l}\mathbf{R}_{\text {rup }} \\
\text { (km) }\end{array}$ & $\begin{array}{c}\text { PGA } \\
\text { (g) }\end{array}$ & $\begin{array}{l}\mathbf{R}_{\text {rup }} \\
\text { (km) }\end{array}$ \\
\hline CACS & 0.2 & 11.7 & 0.02 & 13.1 & 0.21 & 12.8 & 0.14 & 16.2 & 0.07 & 19.4 & 0.08 & 16.7 \\
\hline CBGS & 0.16 & 14.4 & 0.27 & 4.4 & 0.5 & 4.7 & 0.16 & 7.6 & 0.16 & 12.9 & 0.21 & 10.2 \\
\hline $\mathrm{CCCC}$ & 0.22 & 16.2 & 0.23 & 2.6 & 0.43 & 2.8 & - & - & 0.13 & 11.1 & 0.18 & 8.7 \\
\hline $\mathrm{CHHC}$ & 0.17 & 14.7 & 0.16 & 3.5 & 0.37 & 3.8 & 0.22 & 6.8 & 0.17 & 12.5 & 0.22 & 10.0 \\
\hline HPSC & 0.15 & 21.7 & 0.05 & 6.6 & 0.22 & 3.9 & 0.26 & 5.5 & 0.2 & 6.12 & 0.26 & 3.2 \\
\hline KPOC & 0.34 & 27.6 & 0.01 & 19.8 & 0.2 & 17.4 & 0.1 & 19.4 & - & - & - & - \\
\hline NNBS & 0.21 & 23.1 & 0.04 & 7.8 & 0.67 & 3.8 & 0.2 & 5.6 & - & - & - & - \\
\hline PPHS & 0.22 & 15.3 & 0.09 & 8.2 & 0.21 & 8.6 & 0.12 & 10.4 & 0.12 & 13.4 & 0.14 & 10.5 \\
\hline PRPC & 0.21 & 19.3 & 0.09 & 3.7 & 0.63 & 2.5 & 0.34 & 3.7 & 0.29 & 8.1 & - & - \\
\hline REHS & 0.25 & 15.8 & 0.25 & 4.4 & 0.52 & 4.7 & 0.26 & 6.8 & 0.2 & 11.5 & 0.25 & 8.8 \\
\hline RHSC & 0.21 & 10.0 & - & - & 0.28 & 6.5 & 0.19 & 11.8 & 0.16 & 17.2 & 0.16 & 14.6 \\
\hline SHLC & 0.18 & 18.6 & 0.16 & 5.6 & 0.33 & 5.1 & 0.18 & 6.3 & 0.26 & 9.1 & 0.28 & 6.1 \\
\hline SMTC & 0.18 & 17.5 & 0.03 & 10.5 & 0.16 & 10.8 & 0.09 & 12.0 & 0.07 & 13.2 & 0.15 & 10.4 \\
\hline
\end{tabular}

Notes:

1) PGA values from [15] for Darfield, Christchurch, $13 \mathrm{JUN}$ 11, and 23 DEC $11\left(\mathrm{M}_{\mathrm{w}} 5.9\right)$ events; values for 23 DEC $11\left(\mathrm{M}_{\mathrm{w}} 5.8\right)$ and 26 DEC 10 events are from metadata provided by Bradley (2013) pers. comm.

2) $R_{\text {rup }}$ values from [15] for Darfield, Christchurch, 13 JUN 11, and 23 DEC $11\left(M_{w} 5.9\right)$ events; values for 23 DEC $11\left(M_{w} 5.8\right)$ and 26 DEC 10 events are from metadata provided by Bradley (2013) pers. comm. 
Table 3: Site investigation information for strong motion station sites

\begin{tabular}{|c|c|c|c|c|c|c|}
\hline \multirow[b]{2}{*}{$\begin{array}{l}\text { Station } \\
\text { ID }\end{array}$} & \multirow[b]{2}{*}{ Latitude } & \multirow[b]{2}{*}{ Longitude } & \multirow{2}{*}{$\begin{array}{l}\text { Depth to } \\
\text { Riccarton } \\
\text { Gravel }^{(1)} \\
\text { (m) }\end{array}$} & \multicolumn{3}{|c|}{ Available Site Investigation Data } \\
\hline & & & & $\begin{array}{l}\text { Geophysical } \\
\text { Testing }^{(4)}\end{array}$ & CPTu ${ }^{(5)}$ & Boreholes ${ }^{(5)}$ \\
\hline CACS & -43.4832 & 172.5300 & $6 / 14$ & $\mathrm{SW}^{(2)}$ & -- & BH-11529A \\
\hline CBGS & -43.5293 & 172.6199 & 21.0 & $\mathrm{SW}^{(2)}$ & CBGS_CPT1 ${ }^{(2)}$ & CBGS_BH1 ${ }^{(2)}, \mathrm{BH} 11793(\mathrm{CGD})$ \\
\hline $\mathrm{CCCC}$ & -43.5381 & 172.6474 & 25.0 & $\mathrm{SW}^{(2)}$ & $\begin{array}{c}\text { CPT484(CGD), } \\
\text { CPT24862(CGD),CPT24865(CGD) }\end{array}$ & BH1759(CGD) \\
\hline CHHC & -43.5359 & 172.6275 & 22.0 & $\mathrm{SW}^{(2)}$ & $\begin{array}{c}\text { CPT425(CGD), CPT12257(CGD), } \\
\text { CPT12258(CGD) }\end{array}$ & $\begin{array}{c}\text { BH1756 (CGD),BH12255(CGD), } \\
\text { BH26682 (CGD) }\end{array}$ \\
\hline HPSC & -43.5016 & 172.7022 & 36.0 & $\mathrm{SW}^{(3)}$ & $\begin{array}{c}\text { CPT47(CGD), } \\
\text { CPT89(CGD),CPT18940(CGD) }\end{array}$ & BH16910 (CGD) \\
\hline KPOC & -43.3764 & 172.6637 & 18.5 & $\mathrm{SW}^{(2)}$ & -- & $\mathrm{KPOC} \_\mathrm{BH} 1^{(2)}$ \\
\hline NNBS & -43.4954 & 172.7180 & 41.0 & $\mathrm{SW}^{(2)}$ & $\begin{array}{c}\text { CPT33695(CGD),CPT1461(CGD) } \\
\text { CPT17254(CGD) } \\
\end{array}$ & $\begin{array}{c}\text { BH30210 (CGD), BH2685 } \\
\text { (CGD),BH30211(CGD) }\end{array}$ \\
\hline PPHS & -43.4928 & 172.6069 & 20.0 & $\mathrm{SW}^{(2)}$ & CPT1497(CGD) & BH34717(CGD), \\
\hline PRPC & -43.5258 & 172.6828 & 28.0 & $\mathrm{SW}^{(2)}$ & CPT1396(CGD), PRPC_CPT2(2) & BH23529 (CGD) \\
\hline REHS & -43.5219 & 172.6351 & 20.0 & $\mathrm{SW}^{(2)}$ & $\begin{array}{c}\text { REHS_CPT1 }{ }^{(2)}, \\
\text { REHS_CPT2 }{ }^{(2)}, \text { CPT386(CGD), } \\
\text { CPT9215(CGD),CPT9217(CGD) }\end{array}$ & BH1735 (CGD), BH21735 (CGD) \\
\hline RHSC & -43.5362 & 172.5644 & $11 / 16$ & $\mathrm{SW}^{(2)}, \mathrm{SW}^{(3)}$ & -- & BH11529 (CGD) \\
\hline SHLC & -43.5053 & 172.6634 & 27.0 & $\mathrm{SW}^{(2)}$ & CPT626(CGD),CPT17584(CGD) & $\begin{array}{c}\text { BH20985(CGD), BH20992(CGD), } \\
\text { BH23531(CGD) }\end{array}$ \\
\hline SMTC & -43.4675 & 172.6139 & 28.0 & $\mathrm{SW}^{(2)}$ & -- & BH14315(CGD) \\
\hline $\begin{array}{l}\text { No } \\
\text { 1) } \\
\text { 2) } \\
\text { 3) } \\
\text { 4) } \\
\text { 5) }\end{array}$ & $\begin{array}{l}\text { S: } \\
\text { Depth to Ricc } \\
\text { Data and resu } \\
\text { Data and resu } \\
\text { SW = surface } \\
\text { CPT and bore }\end{array}$ & $\begin{array}{l}\text { ton Gravel estime } \\
\text { from [11] } \\
\text { from [18] } \\
\text { ave testing } \\
\text { le data from [16] }\end{array}$ & from the site i & stigation data pres & nted by [11] and Bradley (2014) pers. comm. & \\
\hline
\end{tabular}



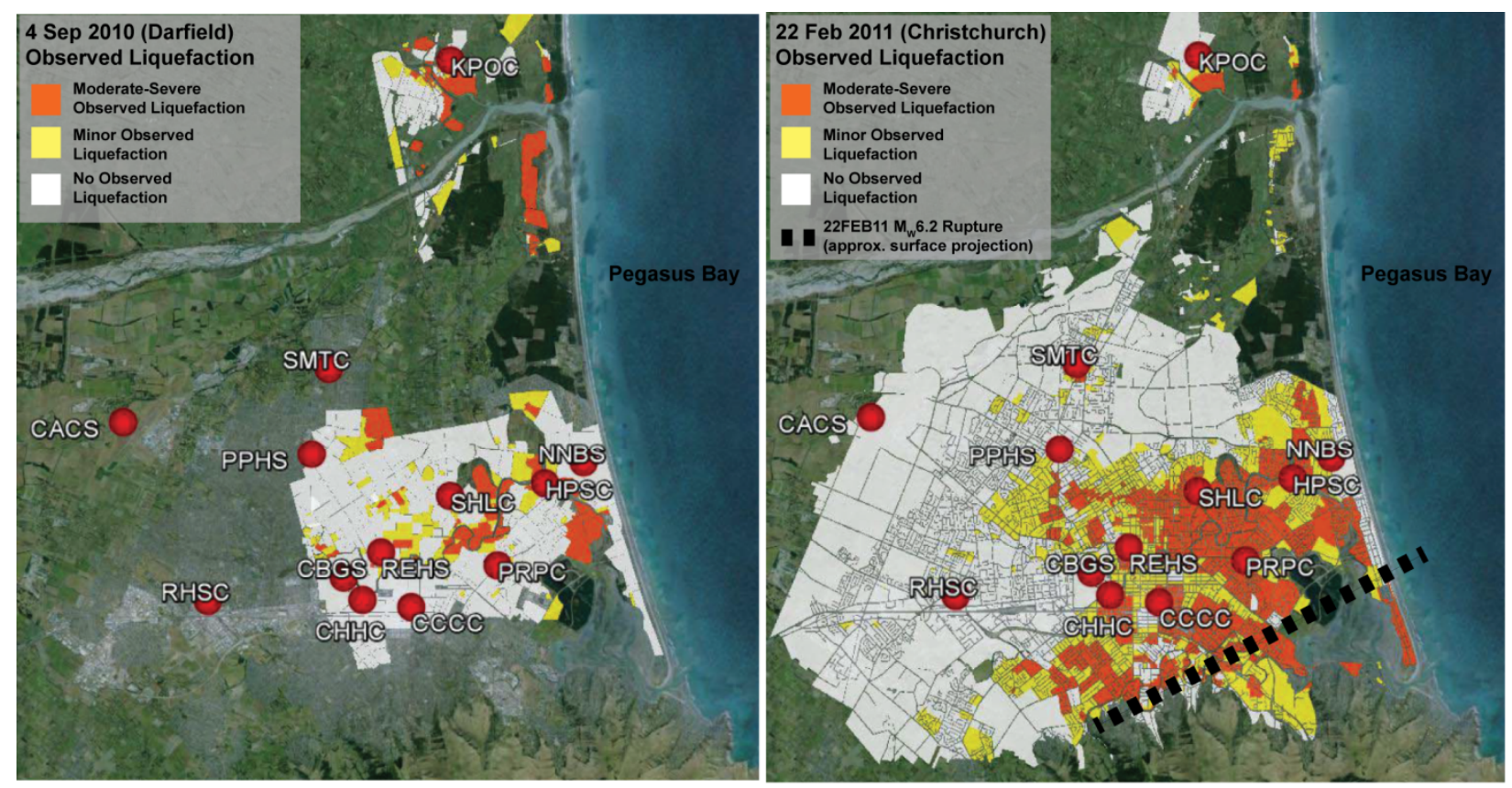

\section{Google earth}

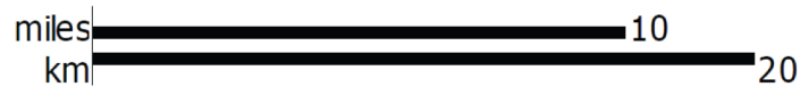

Figure 1: Observed liquefaction maps for the 4 SEP 10 and 22 FEB 11 events [10] 

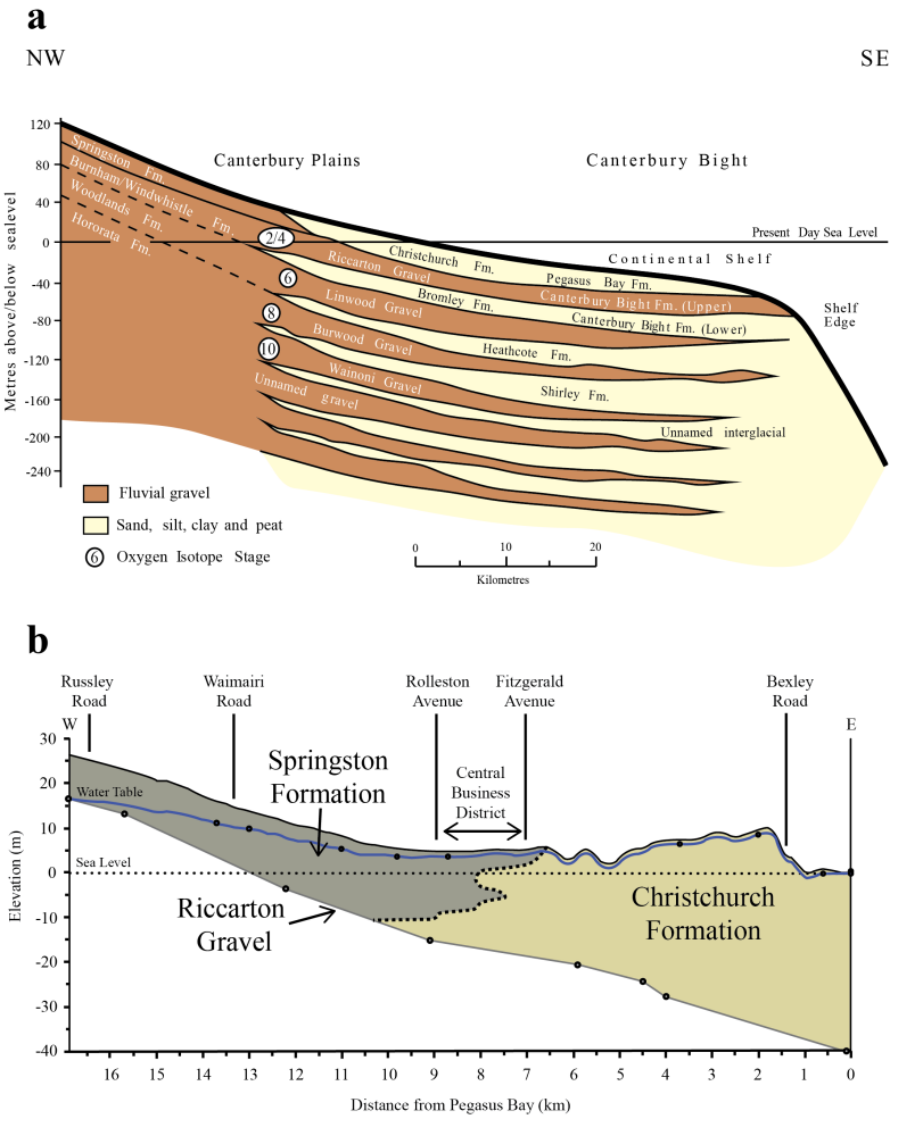

Figure 2: a) Geologic cross section of the Christchurch area (modified after [22]—originally from [20] and [29]) and b) Simplified subsurface profile for Christchurch (modified after [19]) 

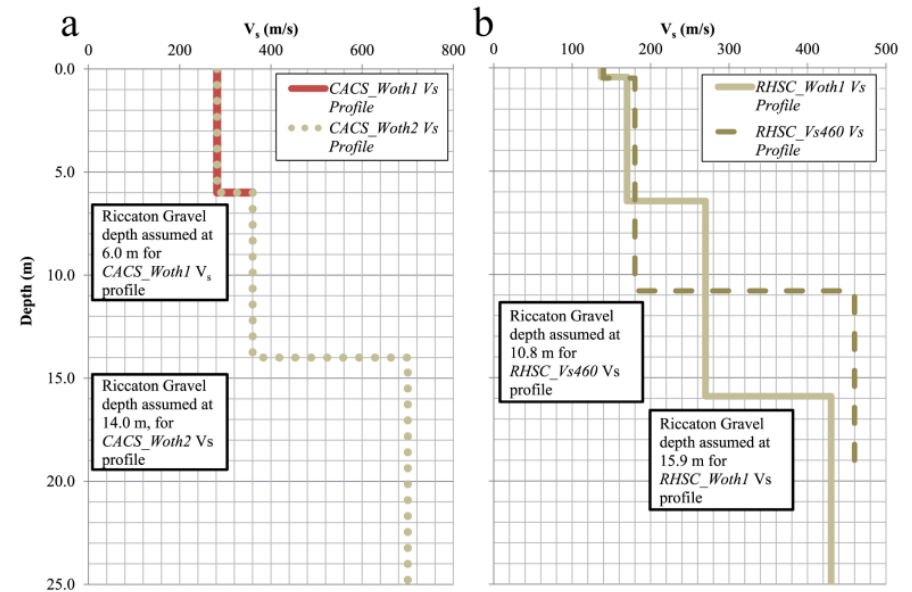

Figure 3: Assumed $\mathrm{V}_{\mathrm{s}}$ profiles for a) CACS and b) RHSC 

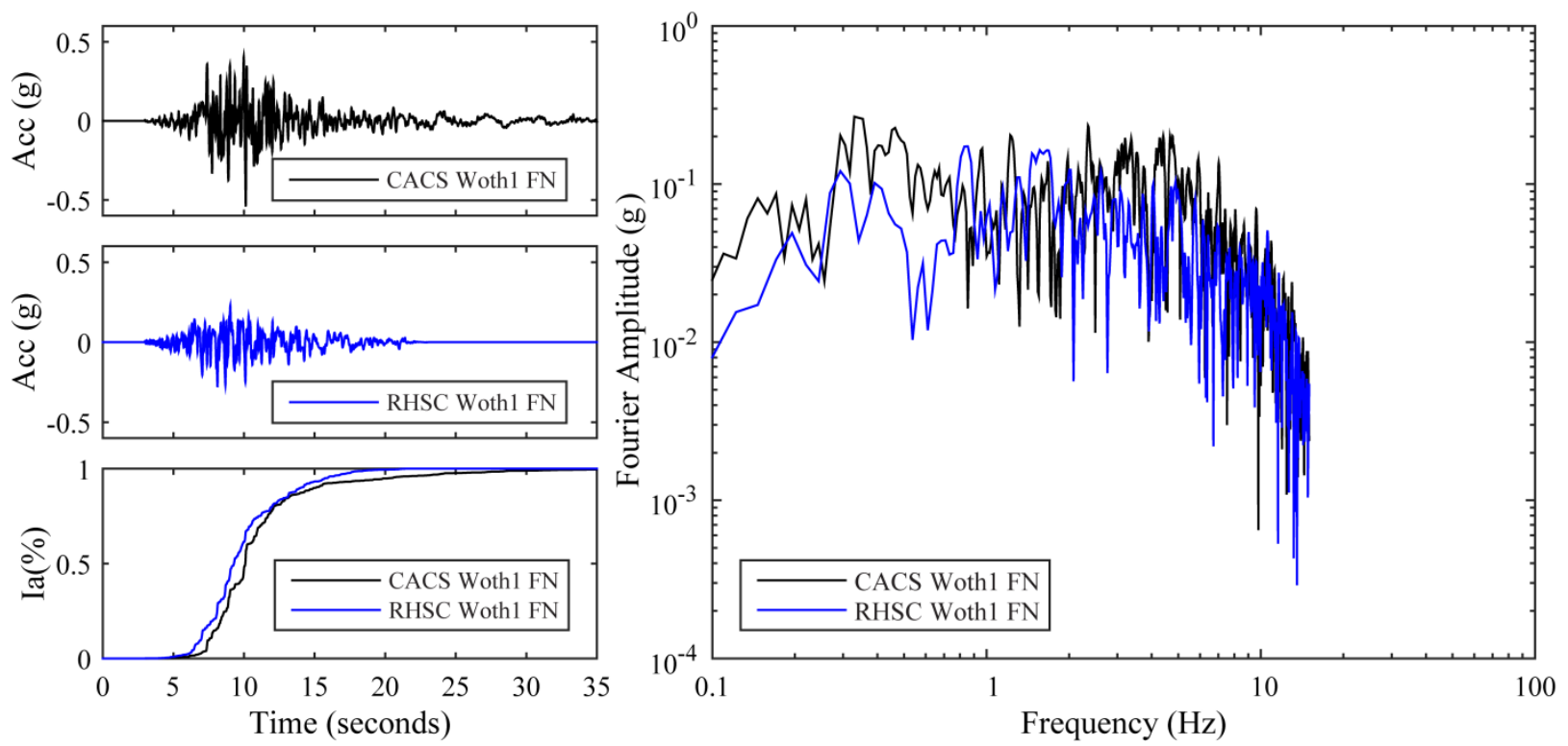

Figure 4: Input motions for site response analyses completed at CHHC for the 22 FEB $11 \mathrm{M}_{\mathrm{w}} 6.2$ Christchurch event; includes Husid plot and Fourier amplitude spectra 

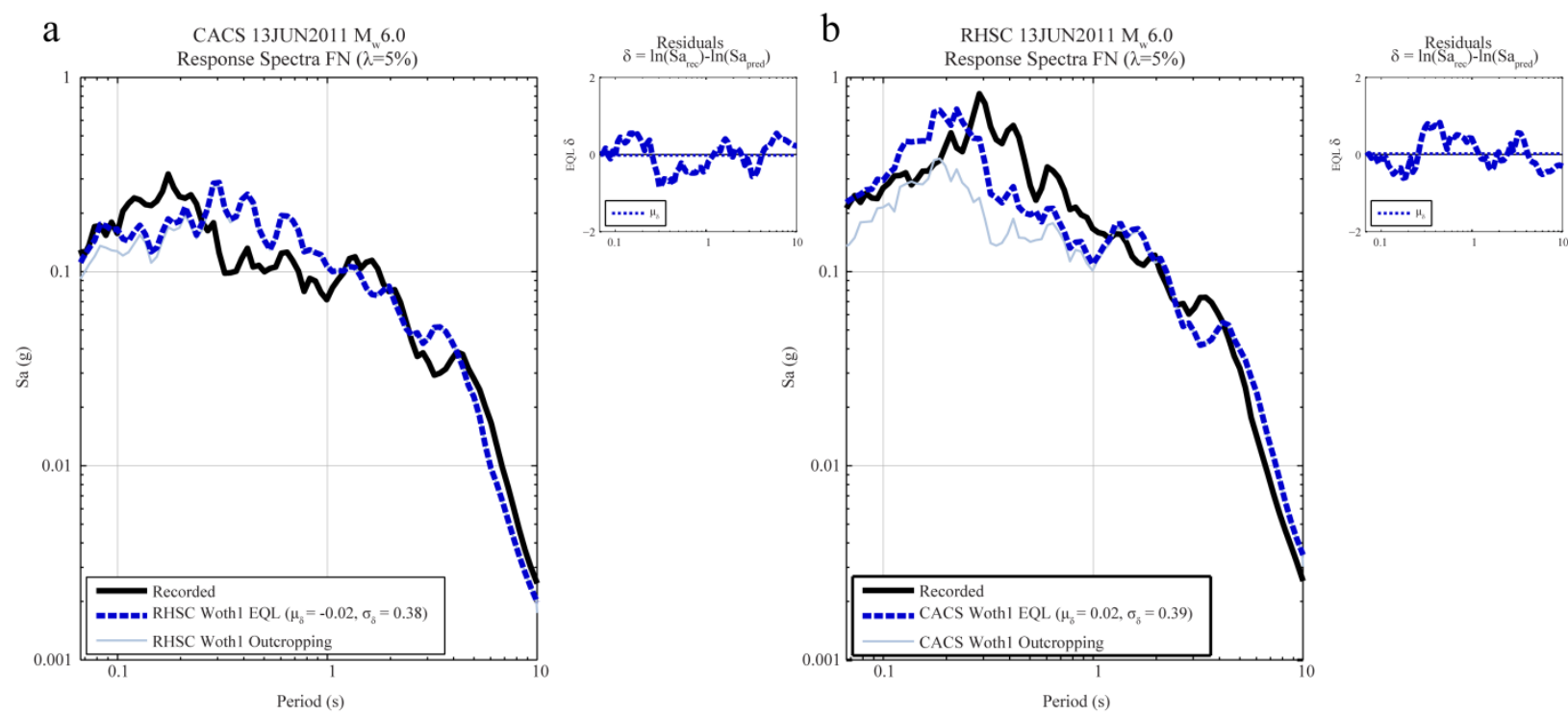

Figure 5: Results of equivalent linear analyses conducted at a) CACS using RHSC Woth1 input motion and b) RHSC using CACS Woth1 input motion in the fault normal (FN) direction for the 13 JUN $2011 \mathrm{M}_{\mathrm{w}} 6.0$ event 

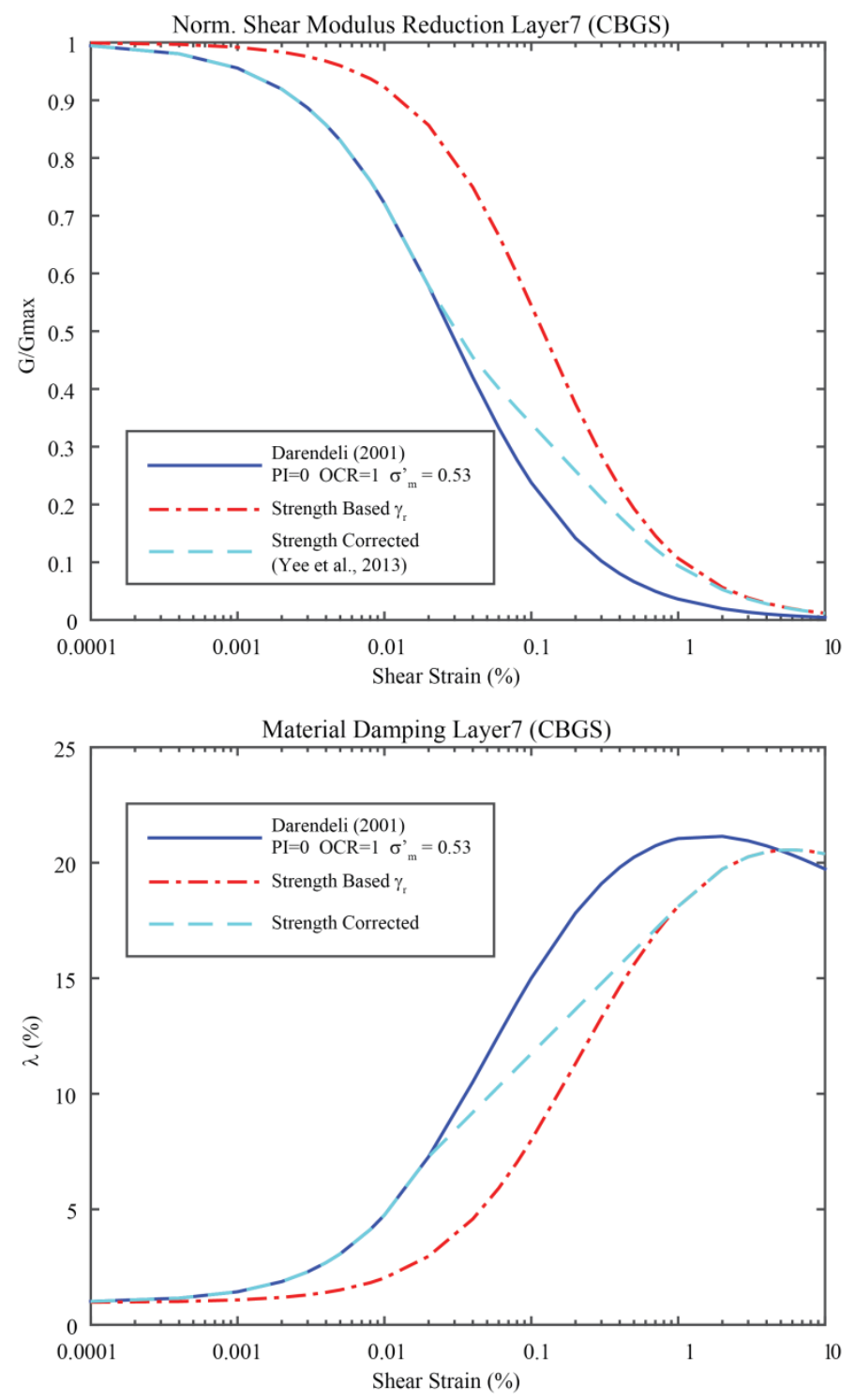

Figure 6: Adjustment of target curves for shear modulus reduction and material damping 

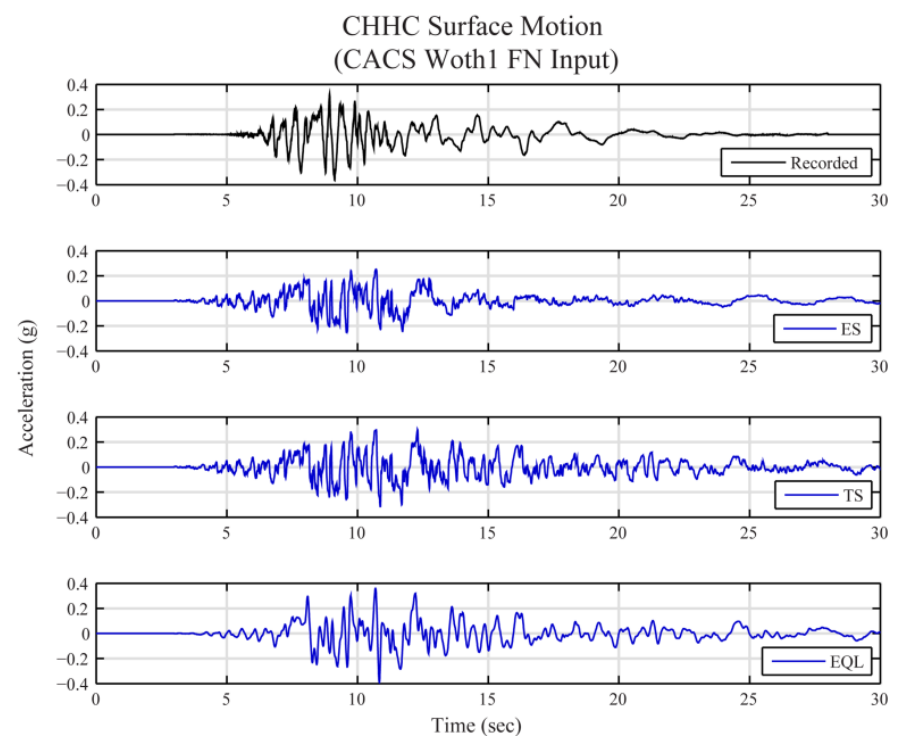

Figure 7: Acceleration-time series for analyses at CHHC using CACS Woth1 input motion in the FN direction for the Christchurch earthquake 
CHHC 22FEB11 $\mathrm{M}_{\mathrm{w}} 6.2$

Response Spectra FN $(\lambda=5 \%)$

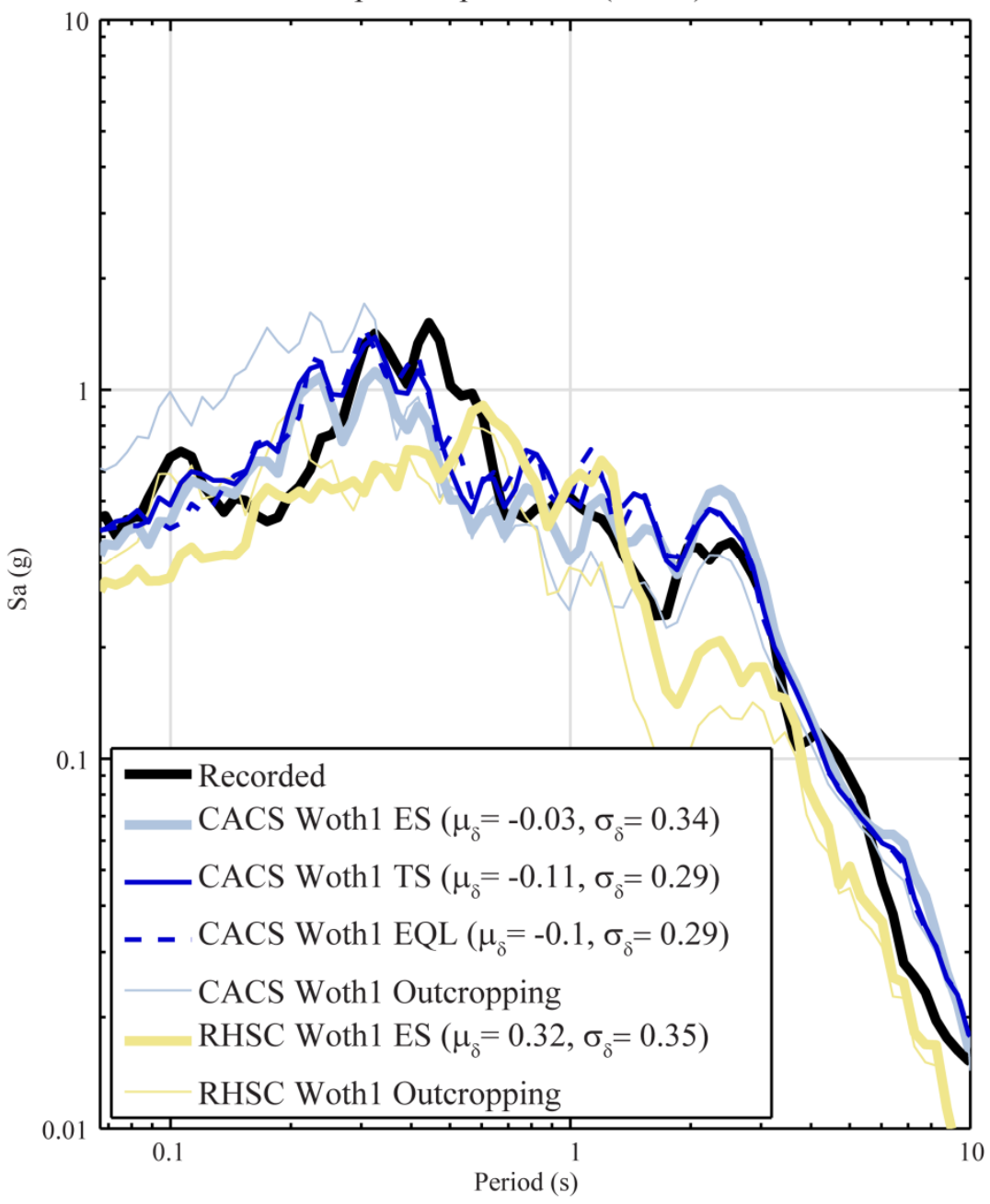

Residuals $\delta=\ln \left(\mathrm{Sa}_{\text {rec }}\right)-\ln \left(\mathrm{Sa}_{\text {pred }}\right)$
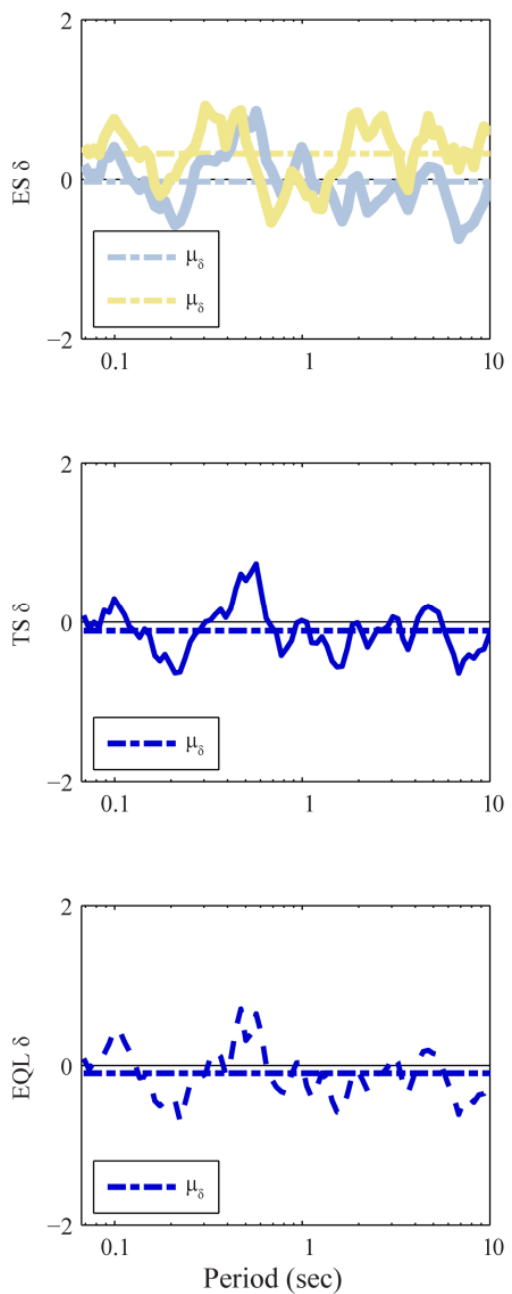

Figure 8: Acceleration response spectra comparisons for $\mathrm{CHHC}(\mathrm{FN})$ site for the Christchurch earthquake 


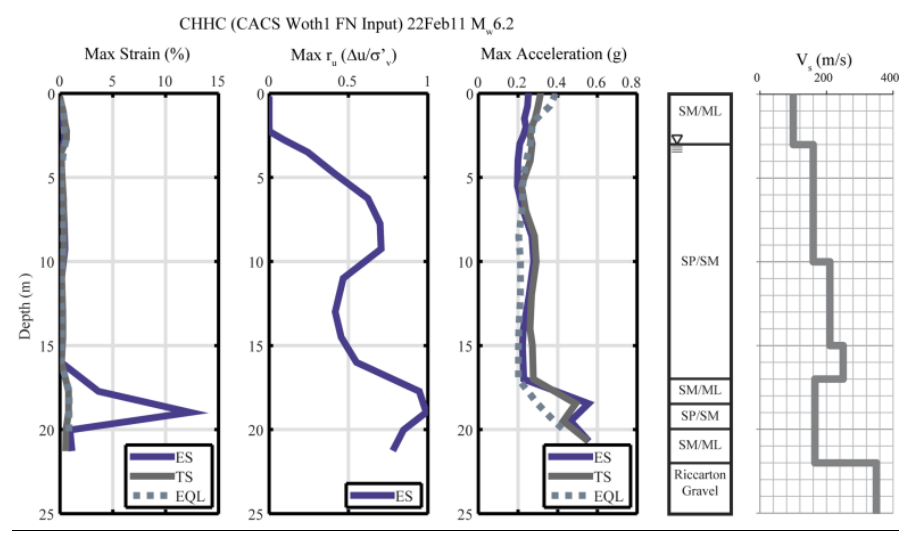

Figure 9: Maximum shear strain, pore pressure ratio, and acceleration values with depth for analyses completed at $\mathrm{CHHC}$ for the Christchurch earthquake using CACS Woth1 FN input motion 
PPHS 04SEP $10 \mathrm{M}_{\mathrm{w}} 7.1$

Response Spectra FP $(\lambda=5 \%)$

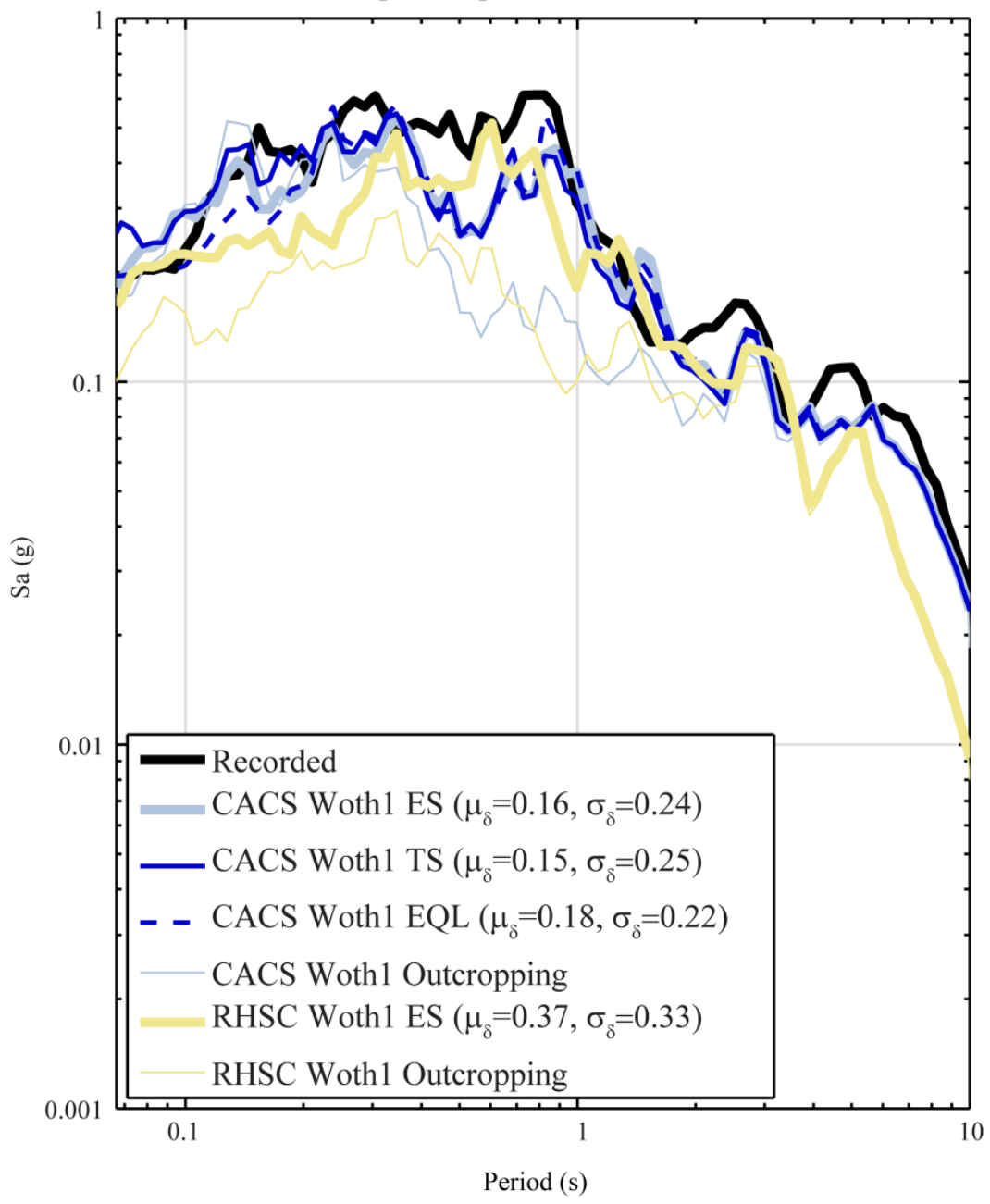

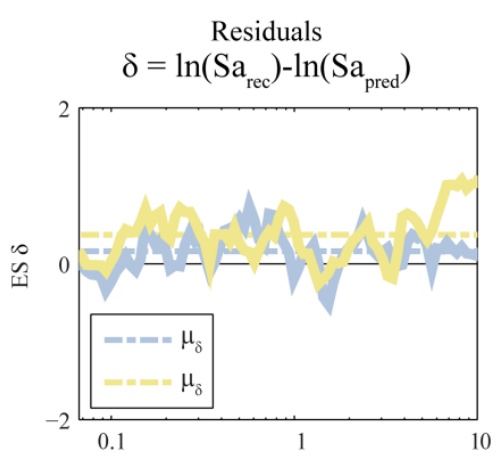
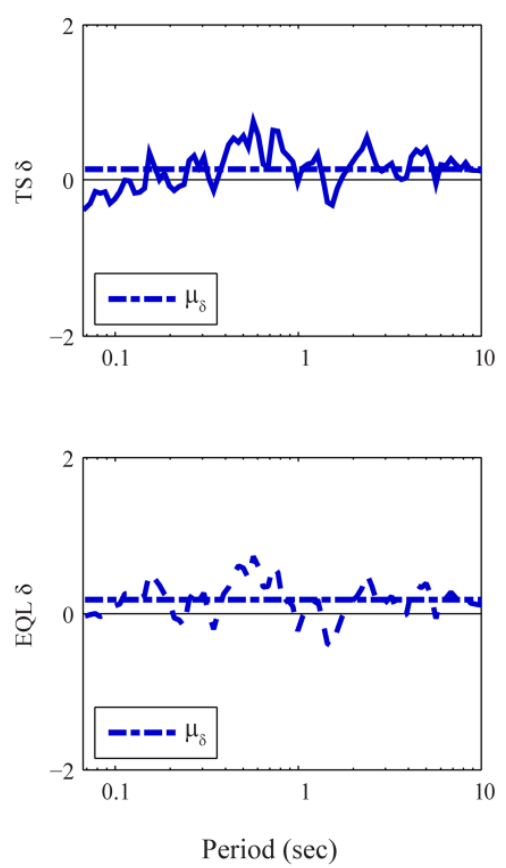

Figure 10: Acceleration response spectra comparisons for PPHS (FP) for the Darfield earthquake 


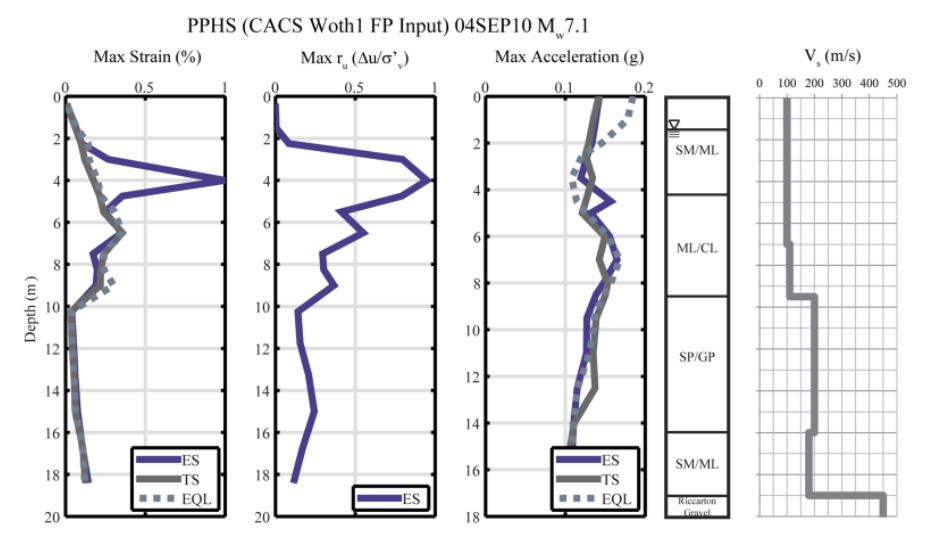

Figure 11: Maximum shear strain, pore pressure ratio, and acceleration values with depth for analyses completed at PPHS for the Darfield earthquake using the CACS Woth1 FP input motion 


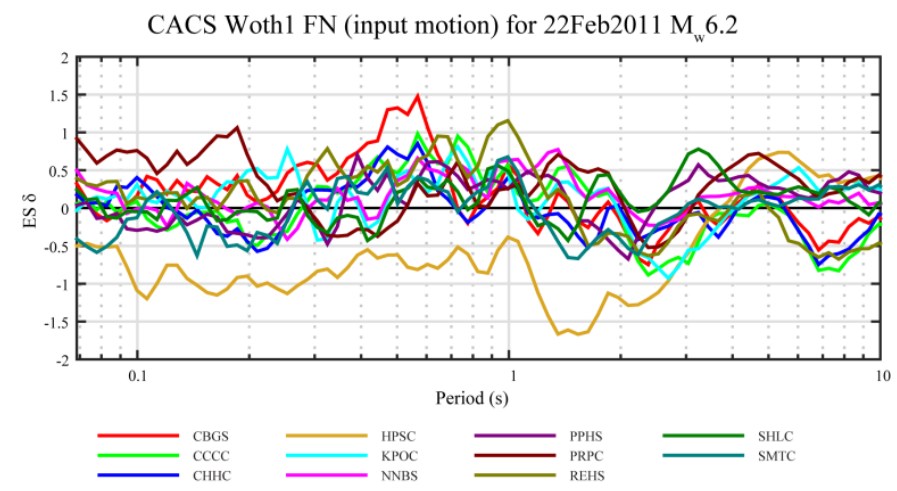

Figure 12: Residuals for effective stress analyses completed using the CACS Woth1 input motion (FN component) for the Christchurch event 

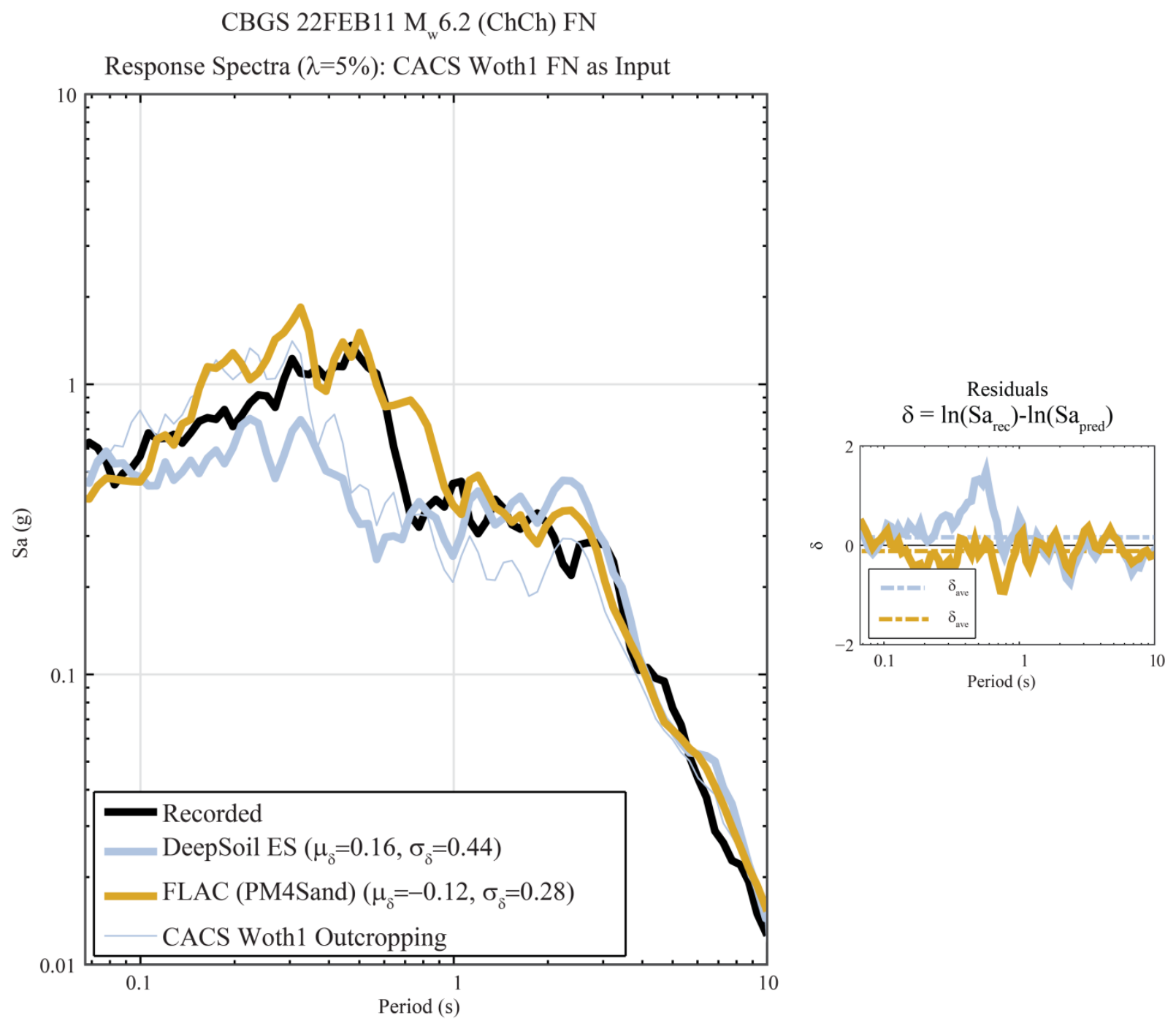

Figure 13: Comparison of acceleration response spectra for calculated surface motions using DEEPSOIL and FLAC (with PM4SAND) for CBGS using the CACS Woth1 FN input motion for the Christchurch event 

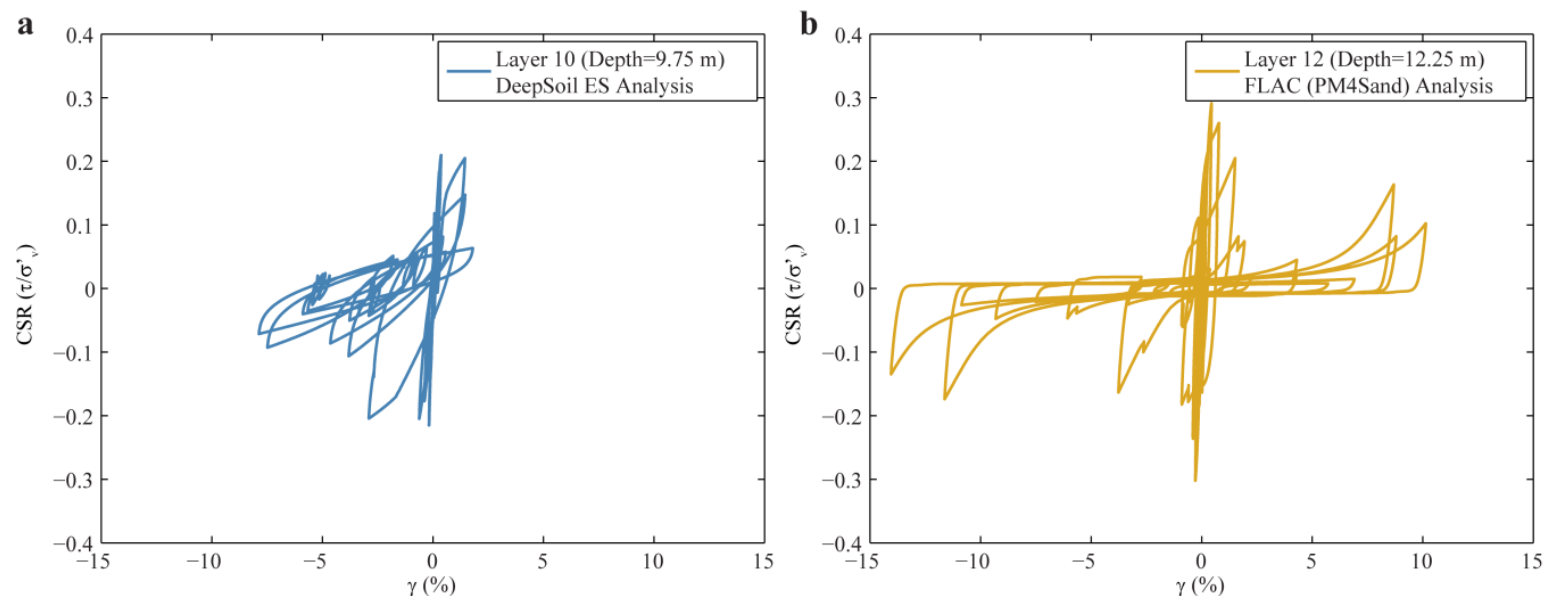

Figure 14: CSR vs. shear strain for a) Layer 10 of the nonlinear effective stress analysis completed using DEEPSOIL and $b$ ) Layer 12 of the analysis completed using FLAC (with PM4Sand) at CBGS for the Christchurch earthquake using the CACS Woth1 FN input motion 


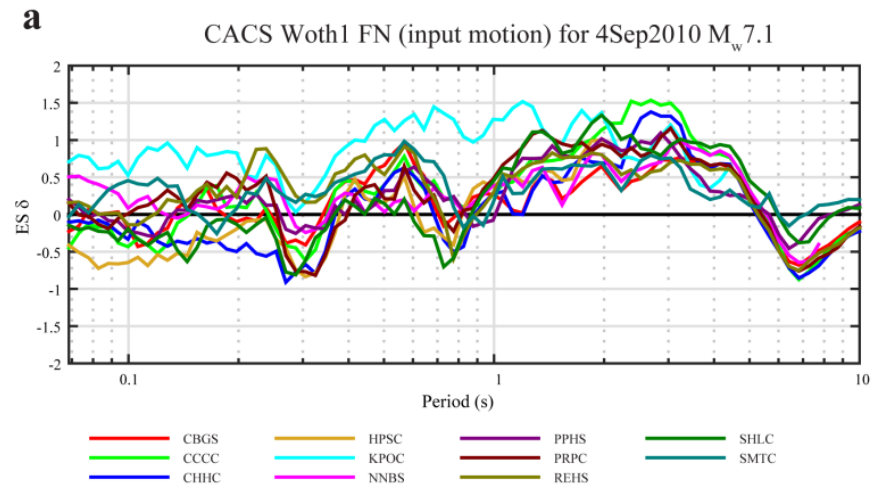

b

RHSC Woth1 FN (input motion) for 4Sep2010 $\mathrm{M}_{\mathrm{w}} 7.1$

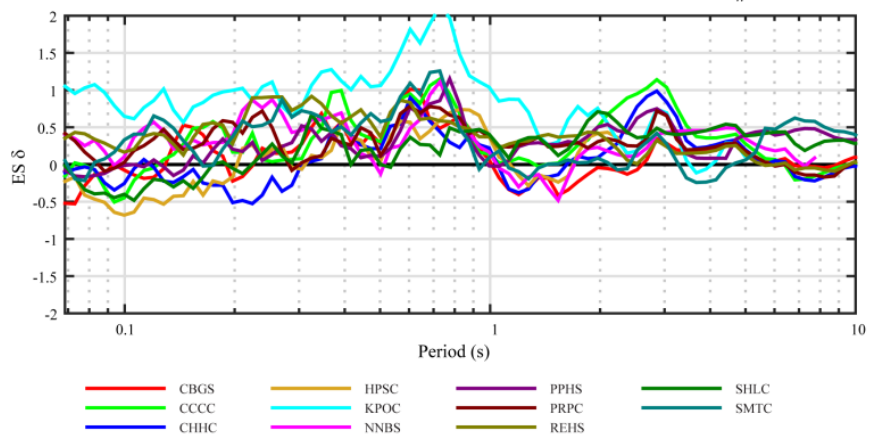

Figure 15: Residuals for effective stress analyses completed using the a) CACS Woth1 non-pulsetype input motion and b) RHSC Woth1 pulse-type input motions (FN component) for the Darfield event 